\title{
Loss-Offset Provisions in the Corporate Tax Code and Misallocation of Capital
}

\author{
Barı̧̧ Kaymak*† $^{* \dagger}$ \\ Université de Montréal and \\ CIREQ \\ Immo Schott ${ }^{\ddagger}$ \\ Université de Montréal and \\ CIREQ
}

February 15, 2019

\begin{abstract}
The corporate tax code allows corporations to write off operating losses against past or future tax obligations, resulting in effective tax rates that are firm-specific and dependent on the history of the firm's performance. Since losses are partly an indication of a drop in productivity, which is generally persistent over time, firms with higher expected productivity face, on average, higher marginal taxes on their investment. In this paper, we analyze the distortionary effects of loss-offset provisions on investment and assess the associated aggregate output losses implied by the misallocation of capital. We find that replacing the corporate income tax with a revenue-neutral value-added tax which eliminates the firm-level differences in effective tax rates leads to a 13.9 percent increase in aggregate output.
\end{abstract}

\footnotetext{
* Department of Economics, Université de Montréal, C.P. 6128 succursale Centre-ville, Montréal, QC H3C 3J7. E-mail: baris.kaymak@umontreal.ca

$\dagger$ The authors acknowledge support from Chaire de la fondation J.W. McConnell en études américaines as well as Social Sciences and Humanities Research Council.

$\ddagger$ Department of Economics, Université de Montréal, C.P. 6128 succursale Centre-ville, Montréal, QC H3C 3J7. E-mail: immo.schott@umontreal.ca
} 


\section{Introduction}

The objective of this paper is to examine the distortionary effects of corporate taxation in the US. Our particular focus lies on the impediments to the efficient allocation of factors in a cross-section of firms. Although the tax code does not distinguish individual firms de jure, special provisions for deductions and allowances can lead to a dispersion in effective marginal tax rates across firms. These firm-specific distortions to investment result in misallocation of capital among firms and reduce aggregate productivity and output.

A significant component of the variation in effective marginal tax rates stems from loss offset provisions. These allow firms to reduce their tax obligations by writing off operating losses against past or future profits. Barring special extensions, firms are currently permitted to carry losses back for up to two years, and forward for up to 20 years. As a result, deductions are prevalent. According to recent IRS statistics on corporate income tax returns, 48 percent of corporations that reported profits claimed a net-operating-loss (NOL) deduction (IRS, 2013). 1 The deductions amounted to 15 percent of the total corporate income in the economy. Because losses often indicate lower levels of productivity, and because productivity is generally persistent over time, firms with higher expected productivity face, on average, higher marginal taxes on their investment. This positive correlation between tax rates and productivity can lead to large losses in aggregate productivity and output (Restuccia and Rogerson, 2008).

We begin our analysis by documenting the heterogeneity in marginal tax rates (MTR) faced by publicly listed firms in the US. We find that loss offset provisions are widely utilized, that the implied dispersion in effective MTR's is large, and that the tax rates are negatively correlated with productivity and size.

Next, we develop a model of tax determination, explicitly incorporating loss-offset provisions and investment decisions in a macroeconomic model of production heterogeneity and business dynamics in the spirit of Hopenhayn and Rogerson (1993). The model permits a formal analysis of the distortionary effects of loss-offset provisions on investment as well as on entry-exit decisions. It also allows us to gauge the distortions to aggregate productivity and output, and examine alternative tax designs in comparison.

We identify three channels through which loss-offset provisions distort investment behavior across firms. The first channel is a direct effect that stems from a common tax design element which frees firms of tax obligations when they run (current) operating losses. Firms expecting large profits, i.e. highly productive firms, face a positive marginal tax rate, whereas firms that are going through a slump and are expecting to make losses, effectively face a lower marginal tax rate

\footnotetext{
${ }^{1}$ While our analysis focuses on US corporations, loss-offset provisions are universal to tax systems around the world and are also seen in the taxation of non-corporate business entities in varying degrees.
} 
on their investment. The second channel stems from the systematic history dependence introduced by loss-offset policies: firms that ran operating losses in the past face a lower marginal tax rate on their future investments. To the extent that productivity and profitability are linked and persistent, this results in higher effective MTR's on more productive firms. The third channel results from a strategic tax optimization behavior as current income has implications for future marginal tax rates.

We calibrate the parameters of the model to match the salient features of the US economy, such as the prevalence of corporate losses and carry forward deductions. Then we simulate policy reforms in order to gauge the implications of loss-offset provisions for aggregate investment and output. In the simulations we focus on long-run equilibria with constant labor supply, where investment responds to the new tax policy. In particular, we compare the benchmark economy to one where the corporate income tax is replaced by a value-added tax that generates the same tax revenue as the corporate income tax. A value-added tax eliminates firm-level differences in capital-labor ratios introduced by the corporate income tax and allows for a uniform taxation of businesses. The upshot of our computations is that aggregate output increases by 13.9 percent. This comes with a 1.4 percent increase in average TFP of incumbent firms and a large increase in the aggregate capital stock.

The productivity gains stem not only from a better allocation of factors across incumbents, but also from a stronger connection between profitability and firm survival, which is normally obscured by loss-offset provisions in the tax code. Simulations from a version of the model with random entry and exit predict a more modest output gain of 7.2 percent.

Improvements in output and TFP under a VAT system come from the elimination of crosssectional heterogeneity in MTR's on capital as well as the equalization of MTR's between capital and labor. Equating MTR's on capital can also be achieved with a full loss-offset, where firms are subsidized immediately when they incur a loss. Our simulations suggest that switching to full offset raises output by $5.1 \%$, but reduces tax revenue by $18 \%$. Raising the tax rate to make up for the lost revenue undoes the improvements in output. We find the elimination of the provision to carry losses across time to be a more viable option. While this does not fully homogenize MTR's, it nonetheless improves TFP by $1.3 \%$ and output by $1.9 \%$ all the while raising the same tax revenue. When we eliminate carry forward and carry back provisions individually, we find carry forward rules to be more distortionary.

Recent research documents a wide dispersion in measured marginal products of capital and labor across establishments and argues that the loss in output due to misallocation of inputs is potentially large (Hsieh and Klenow, 2009). Latest estimates suggest that the US could raise its output by as much as 25 percent if inputs were reallocated to equalize marginal products across plants (Bils, Klenow, and Ruane, 2017). A vibrant literature has followed aiming to identify the 
sources of misallocation. One strand has examined the role of credit frictions on the misallocation of capital (e.g. Midrigan and Xu (2014); Buera, Kaboski, and Shin (2011); Greenwood, Sanchez, and Wang (2010)). However, the implied losses in aggregate productivity appear to be quantitatively small relative to what the empirical studies find. Similarly, David and Venkateswaran (2017) examine the implications of capital adjustment costs for misallocation, and conclude that the implied effect on aggregate productivity is fairly small 2 Asker, Collard-Wexler, and De Loecker (2014) find that a large share of the dispersion in capital productivity across industries can be explained by the volatility of productivity. This sort of ex-post dispersion has more to do with the uncertainty of running a business, and is arguably of less interest to policy makers. David and Venkateswaran (2017) find, however, that much of total misallocation stems from (unidentified but measurable) firm-specific distortions within industries that are size/productivity dependent (see also Guner, Ventura, and Xu (2008) on size dependent distortions). This is consistent with the empirical literature that examines distortions within narrowly defined industries. Our paper contributes to the literature by identifying an institutional source of misallocation, quantitatively assessing its effect on aggregate output, and proposing a concrete policy to remedy it.

Our paper is also related to an earlier literature that studied the implications of tax asymmetries in the corporate tax code and its impact on investment. Domar and Musgrave(1944) were the first to argue that a lack of full loss provision is tantamount to limited risk sharing with the government and discourages risk taking. A similar analysis can be found in Stiglitz (1969). Carry forward rules were seen as a shortcut to achieve full loss offset without explicitly transferring resources to firms in the event of a loss. In this vein, Auerbach (1986) provides a theoretical analysis of asymmetries that can arise from loss-offset provisions in the tax code. The focus in the literature on loss provisions has been on the smoothing of marginal tax rates for a given firm over time, whereas the primary concern in our paper is the equalization of tax rates across heterogeneous firms. In empirical work, Altshuler and Auerbach (1990) find that these provisions can significantly affect firms' investment in equipment. Similarly, Cummins, Hassett, and Hubbard (1994) estimate a significant investment response to corporate taxes. In corporate finance, Graham, Lemmon, and Schallheim (1998) find that the marginal corporate tax rate is instrumental for financing decisions at the firm level.

The next section documents the heterogeneity in effective marginal tax rates among publicly listed firms in the US. Section 3 presents the model and Section 4 describes the different distortions to investment from corporate taxation and loss offset provisions. The parameter calibration for the US economy is presented in Section 5. Results from tax reform simulations are reported in Section 6. Section 8 concludes.

\footnotetext{
${ }^{2}$ Others have also pointed to regulatory distortions, lack of property right enforcement in the context of underdeveloped economies. See Adamopoulos and Restuccia (2014), for instance, or Restuccia and Rogerson (2017) for a recent survey.
} 
Figure 1: Distribution of Marginal Tax Rates

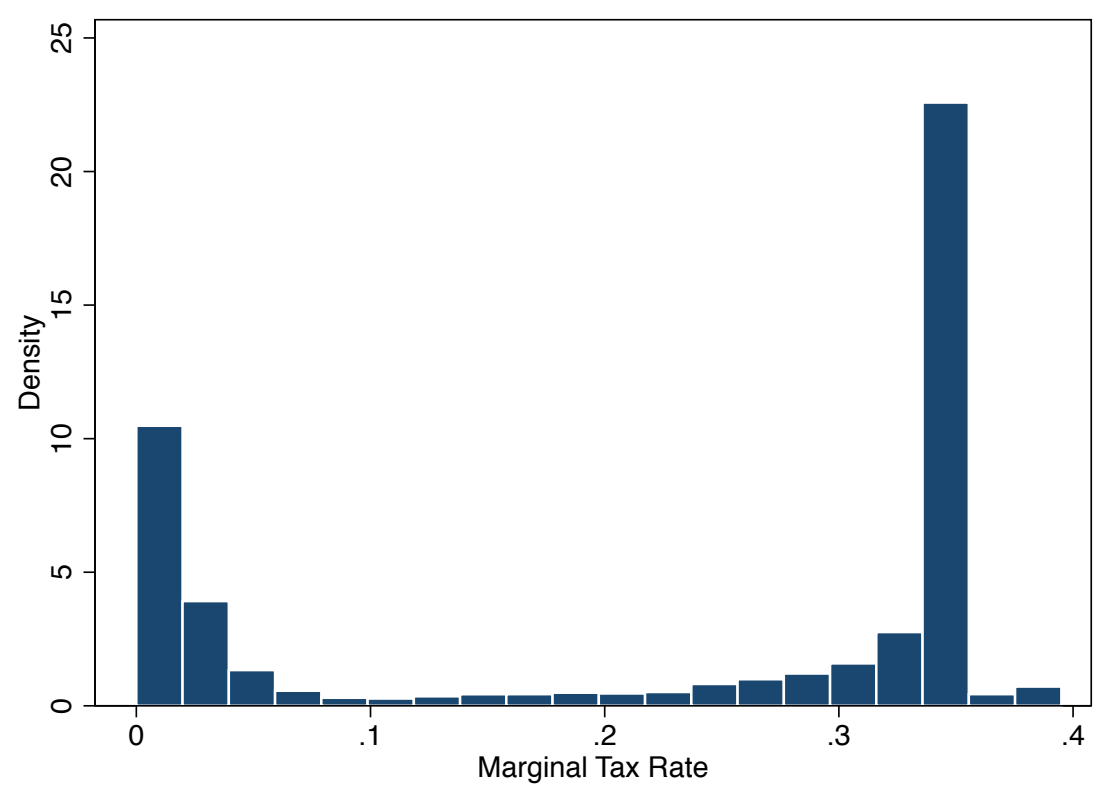

Note.- Figure shows the distribution of effective marginal corporate tax rates among firms with positive pretax income. Source: Compustat 1988 - 2015.

\section{An Empirical Analysis of Tax Rate Heterogeneity}

In this section, we document the distribution of effective marginal tax rates among publicly listed companies available in the Compustat database. We focus on years between 1988 to 2015, during which the statutory rates have been stable. Because the official tax records are confidential, the literature has relied on estimates of the marginal tax rate. We use simulated rates obtained from Graham and Mills (2008) which contain two measures of the marginal tax rates, one before deductions are applied, MTR $_{B}$, and one after all deductions, MTR $]^{3}$ The distribution of the effective marginal tax rates after all deductions, MTR, is shown in Figure 1 . Most firms are either subject to a very small or zero marginal tax rate or face around the top marginal tax rate of 35 percent. $4^{4}$ The average MTR is 22 percent with a standard deviation of 15 percent.

To compare the characteristics of firms with different tax rates, Table 1 shows measures of size and productivity by terciles of the MTR distribution. The average marginal tax rate paid by the bottom third of the distribution is effectively 0 percent, followed by 9 percent and 34 percent for the middle and top thirds. The second column shows the effective the pre-deduction rates

\footnotetext{
${ }^{3}$ The simulated tax rates provide a close approximation of the actual taxes paid as reported in tax records. See Graham and Mills (2008) and Graham (1996) for further details.

${ }^{4}$ The top marginal tax rate is defined as the rate that applies to largest profits. Since the corporate tax rate becomes regressive at high levels of profits, the highest marginal tax rate of 39 percent applies instead to those with medium to high levels of profits.
} 
Table 1: Size, Productivity and Marginal Tax Rates

\begin{tabular}{lccccrrr}
\hline Tercile & MTR & MTR $_{B}$ & TLCF & $\log \mathrm{L}$ & $\log \mathrm{K}$ & $\log$ TFP & $\log (\mathrm{Y} / \mathrm{K})$ \\
\hline Bottom & 0.00 & 0.17 & 0.90 & -0.95 & -1.08 & -0.36 & -0.22 \\
Middle & 0.09 & 0.24 & 0.78 & 0.00 & 0.00 & 0.00 & 0.00 \\
Top & 0.34 & 0.34 & 0.04 & 1.14 & 0.84 & 0.18 & 0.34 \\
\hline
\end{tabular}

Note.- Table shows the averages by terciles of the effective MTR distribution. Variables in logs are purged of year effects, and are normalized to zero for the middle third of the distribution. Data comes from Compustat US (19882015). See Appendix D for variable definitions and sample selection.

that would have otherwise applied to these firms. These are considerably higher than the average marginal rates paid by the firms in the bottom and middle terciles. The third column shows the fraction of firms that have eligible tax-loss carry forward (TLCF) deductions. Firms with the highest effective MTR's do not have these deductions, and pay close to their statutory rates. The remaining columns show (log) measures of size and productivity for each tax category. The values for the median group are normalized to zero. Firms that face higher effective corporate tax rates are larger and more productive on average. The last column reports average productivity of capital for each group, and indicates a strong positive connection to the effective MTR.

To better understand the cross-sectional distribution of effective MTR's, we regressed the effective MTR on employment, capital and productivity, controlling for year fixed effects. The results are shown in the first column of Table 2. A 1 percent increase in employment is associated with a 2.3 percent higher tax rate at the margin. Similarly, a 1 percent increase in TFP corresponds to a 2.4 percent increase in the tax rate. By contrast, a larger capital stock is associated with a 0.55 percent reduction in the MTR, controlling for employment and TFP. These correlations are primarily generated by loss-offset rules. This is shown in the second column, where we control for whether the firm possesses any eligible carry forward deductions. Firms that do pay on average 27 percentage points lower tax rates at the margin. Furthermore, the coefficients on employment and TFP are reduced by two thirds. This indicates that a main reason for why smaller, less productive firms face lower marginal tax rates is because they have experienced losses in the recent past. The negative association between the capital stock and the MTR disappears completely. This is because firms with larger capital stocks, conditional on employment and TFP, have higher depreciation expenses relative to income and are more likely to run losses. Once these are accounted for, they have similar tax obligations. The last column in Table 2 examines the relation between TLCF's and firm characteristics. Generally, firms that are larger in terms of employment, or are more productive, are less likely to be eligible for TLCF deductions. Firms with larger capital stocks are more likely to have TLCF deductions. 
Table 2: Cross-Sectional Correlates of MTR and Carry Over Status

\begin{tabular}{lccc}
\hline dependent variable: & MTR & MTR & TLCF \\
\hline log employment & $2.25^{* * *}$ & $0.66^{* * *}$ & $-5.20^{* * *}$ \\
& $(0.13)$ & $(0.07)$ & $(0.48)$ \\
log capital & $-0.55^{* *}$ & -0.08 & $1.56^{*}$ \\
& $(0.11)$ & $(0.06)$ & $(0.43)$ \\
log TFP & $2.36^{* * *}$ & $0.87 * * *$ & $-4.27 * * *$ \\
& $(0.17)$ & $(0.07)$ & $(0.63)$ \\
has TLCF & & $-0.27 * * *$ \\
& & $(0.00)$ \\
\hline $\mathrm{N}$ & 38,766 & 38,766 & 40,643 \\
\hline$* p<0.05, * * p<0.01, * * * p<0.001$ &
\end{tabular}

Note.- Table shows the correlates effective marginal tax rates and the incidence of tax-loss carry forward (TLCF) at the firm level. All columns control for indicators for year. Standard errors are clustered by firm and are reported in parentheses. Data comes from Compustat US (1988-2015)

Finally, to gauge the impact of losses on marginal tax rates, we regressed the MTR on lags of an indicator for past losses, controlling for year effects and the level of firms' current profits 5 To capture the carry over provisions, lags going as far back as 10 years were included in the regression. Figure 2 shows the estimated coefficients for the loss indicator along with 95 percent confidence bands. The marginal tax rate changes significantly depending on the presence of past losses. A firm that made a loss in the previous year experiences, on average, a 6 percentage point reduction in its marginal tax rate. Since losses can be carried forward for 20 years, the loss indicator remains significant for higher lags, albeit with a smaller coefficient, likely because earlier losses have already been used for a deduction.

Next, we present the model.

\section{A Model of Corporate Taxation with Industry Dynamics}

The model we employ is a general equilibrium model of industry dynamics in the spirit of Hopenhayn and Rogerson (1993) to which we add capital and certain aspects of the corporate tax system.

\footnotetext{
${ }^{5}$ Since the statutory tax rates are non-linear, we included dummy variables for 20 quantiles of the income distribution to control for the effect of current income on the tax rates. Firms that make losses or do not owe taxes for other reasons prior to any deductions were therefore excluded from the regression sample.
} 
Figure 2: Impact of Loss-offset Provisions on the Marginal Tax Rate

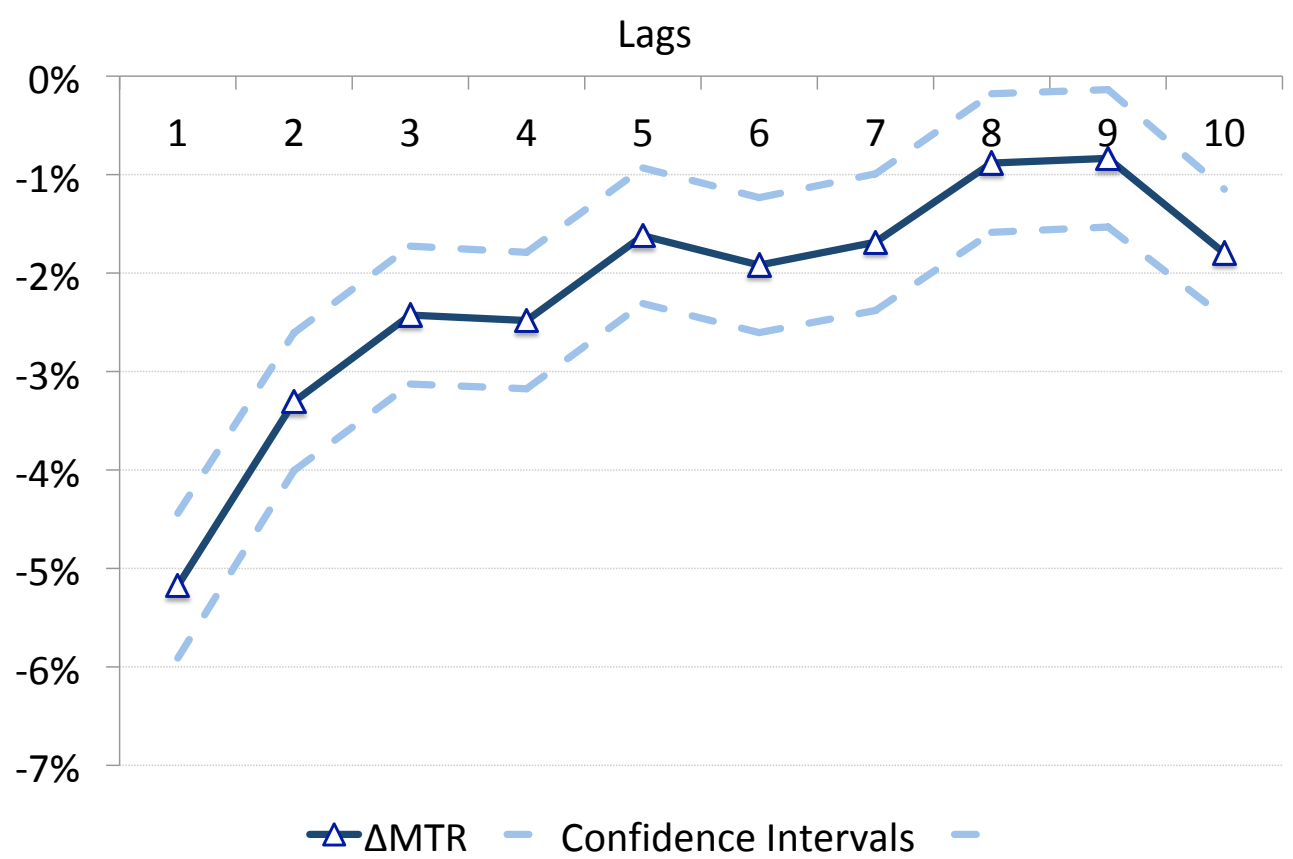

Note.- Figure shows the estimated impact of past losses on the current marginal tax rate. Dashed lines are the corresponding confidence bands. The horizontal axis shows the years since a loss has incurred.

Time is discrete and the horizon is infinite. The economy consists of a mass of heterogeneous firms, a representative household, and a government. At time $t$ a positive mass of price-taking firms produces a homogenous good using the following production function

$$
q_{t}=\varepsilon_{t} k_{t}^{\alpha} n_{t}^{\beta}
$$

with $\alpha, \beta \in(0,1)$ and $\alpha+\beta=\gamma<1$, where $\gamma$ denotes the returns to scale. The productivity parameter $\varepsilon_{t}$ is idiosyncratic, and follows the first-order stochastic process

$$
\log \varepsilon_{t}=\rho \log \varepsilon_{t-1}+\sigma_{\varepsilon} \eta_{t}
$$

where $\eta_{t} \sim N(0,1)$ for all $t \geq 0$. Let $H\left(\varepsilon_{t+1} \mid \varepsilon_{t}\right)$ denote the conditional distribution of a firm's productivity, and $H(\varepsilon)$ the associated invariant distribution.

Firms accumulate capital, hire labor services at the wage rate $w_{t}$, and discount future profits with $\rho \in(0,1)$. Capital depreciates at a stochastic rate $\delta \in(0,1)$ following an i.i.d. process denoted by $D(\delta)$. Firms also incur a fixed operational cost of $c_{f}>0$ units of the consumption good each period.

There is a large mass of potential entrants, of whom a constant mass $M>0$ enters the economy 
each period and pays an entry $\cos t c_{e} \geq 0$ in units of the consumption good. The initial productivity level $\varepsilon_{0}$ is drawn from the stationary density $H_{0}(\varepsilon)$. The subsequent evolution of productivity is governed by the conditional density $H\left(\varepsilon_{t+1} \mid \varepsilon_{t}\right)$. Incumbent firms may cease production and exit the industry at the end of a period. Firms that choose to exit are not allowed to re-enter the market at a later period. Upon exit, the firm's remaining capital stock is liquidated and distributed to its shareholders along with any income generated prior to exit.

The representative household supplies labor to the production sector in return for wage income, collects dividends from operational firms and consumes the output.

The government levies taxes on corporate income and redistributes the proceeds to the representative household in a lump-sum fashion, ensuring a balanced budget at all times.

Next, we describe the details of the economic environment and define the problems faced by different agents in the economy.

\subsection{Incumbent Firm's Problem}

The timing of events for incumbent firms is summarized in Figure 3. Each period can be grouped into three stages. The period begins with the production stage, where the state of an incumbent firm is defined by its capital stock, $k_{t}$, determined by past investment choices, its productivity level, $\varepsilon_{t}$, and a summary of its past income performance for tax purposes, $s_{t} \in \mathbb{R}$. Given this state firms hire labor for production and carry out production. Subsequently, realized depreciation expenses along with the fixed cost of operation and wage bill make up the total outlays and determine net income before taxes. Firms then pay corporate income taxes, taking into account any deductions or credits they may be entitled to as determined by $s_{t}$. At this point, next period's tax state, $s_{t+1}$ is determined based on current net income and any remaining loss-offset allowances. In the second stage, firms observe the productivity level $\varepsilon_{t+1}$ for the subsequent production cycle. In the final stage, firms decide whether to cease or continue their operations. If they choose to exit the industry, all income and capital net-of-depreciation is distributed to shareholders. If they decide to continue their operations, they then choose how much to invest in capital, implying next period's capital stock $k_{t+1}$, and distribute any income net-of-investment to shareholders.

Before we formally state the firm's problem we define net operating income in our model as the difference between sales revenue and operational expenses, which include labor costs, depreciation expenses and other fixed production costs:

$$
p \varepsilon k^{\alpha} n^{\beta}-w n-\delta p k-p c_{f}
$$

where $p$ is the price of the consumption good. The operating income is essentially the return on capital investment net of depreciation and other costs and represents the firm's income (or profits) 
Figure 3: Timing of Events for an Incumbent Firm

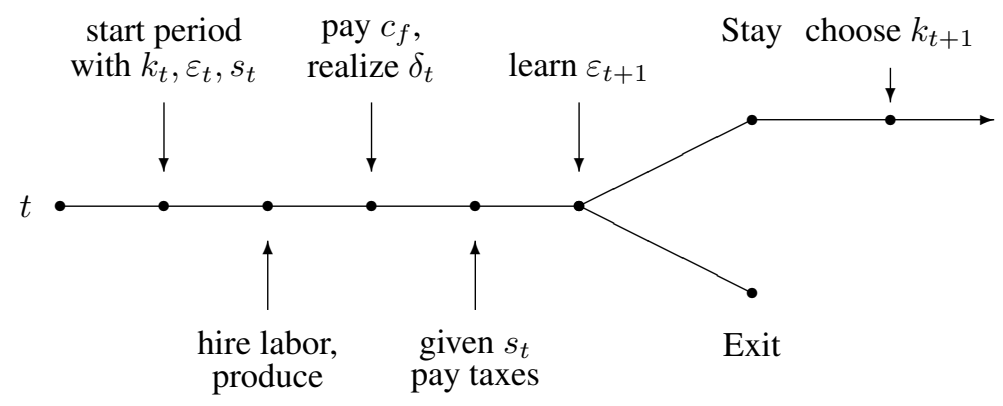

for tax purposes $\sqrt{6}^{7}$ We assume that firms finance capital investments through equity issuance..$^{8}$

Notice that because labor costs are deducted from the tax base, the corporate taxes are effectively levied on capital, i.e. labor demand is not directly affected by the corporate tax rate. Furthermore, since labor demand is static, the optimal level of employment maximizes the expected value of net operating income defined in (2), and can be solved as $n^{*}(k, \varepsilon)=\left[\frac{\beta \varepsilon p k^{\alpha}}{w}\right]^{\frac{1}{1-\beta}}$. This allows us to write firm production net of labor costs as $f(k)=\chi k^{\phi}$, where $\chi$ is a measure of firm profitability. $9^{9}$

The associated profits before taxes are:

$$
\pi^{b}(k, \varepsilon, \delta)=p f(k)-p \delta k-p c_{f}
$$

Next, we formalize the recursive representation of the firm's investment problem beginning with the planning stage, after productivity for the next production cycle is observed. To that end, let $T\left(\pi^{b}(k, \varepsilon, \delta), s\right)$ denote the tax obligations of a firm which depends on its net income as well as any deductions or rebates it might be entitled to, based on $s$. The problem of an incumbent firm is defined by a continuation decision

$$
V(\varepsilon, s)=\max \left\{V^{c}(\varepsilon, s), V^{x}\right\}
$$

where $V^{x}=0$ is the value of exit (with the associated optimal exit policy, $x(\varepsilon, s) \in\{0,1\}$ ), and

\footnotetext{
${ }^{6}$ Throughout the paper, we use the accounting definition of the words profit and loss. This should not be confused with economic profits present in the model due to diminishing returns to scale in production.

${ }^{7}$ Also implicit in our definition is the assumption that tax depreciation is the same as economic depreciation. Actual depreciation allowance rules for capital are complex and may exacerbate the dispersion in effective marginal tax rates (see, for instance, Gravelle (2004)).

${ }^{8}$ See Section 6.5 for a model where firm investments are partially financed with debt.

${ }^{9}$ Specifically, $\phi \equiv \frac{\alpha}{1-\beta}$ and $\chi \equiv(w / p)^{-\frac{\beta}{1-\beta}} \varepsilon^{\frac{1}{1-\beta}} \cdot\left(\beta^{\frac{\beta}{1-\beta}}-\beta^{\frac{\beta}{1-\beta}}\right)$.
} 
the following investment decision if it chooses to remain in operation:

$$
V^{c}(\varepsilon, s)=\max _{k}\left\{-p k(1-\rho)+\rho \mathbb{E}\left[\pi^{b}(k, \varepsilon, \delta)-T\left(\pi^{b}(k, \varepsilon, \delta), s\right)+V\left(\varepsilon^{\prime}, s^{\prime}\right)\right]\right\}
$$

subject to

$$
s^{\prime}=\left(1-\delta^{+}\right)\left(\pi^{b}(k, \varepsilon, \delta)+s\right) \cdot \mathbb{1}_{\pi^{b}+s>0}+\left(1-\delta^{-}\right)\left(\pi^{b}(k, \varepsilon, \delta)+s\right) \cdot \mathbb{1}_{\pi^{b}+s<0},
$$

where the expectation operator in (5) is taken over depreciation, $\delta$, and future productivity, $\varepsilon^{\prime}$. A continuing firm raises $k$ units of capital in the current period (at price $p$ ), and receives income net of taxes plus the expected continuation value in the next period. Let $k^{*}=k(\varepsilon, s)$ denote the associated optimal capital choice, and $\pi^{a}(\varepsilon, s, \delta)=\pi^{b}\left(k^{*}, \varepsilon, \delta\right)-T\left(\pi^{b}\left(k^{*}, \varepsilon, \delta\right), s\right)$ denote the resulting after-tax income.

Equation (6) describes the law of motion of $s$, which is essentially the history of past income performance for tax purposes and reflects the sum of past incomes. We assume that past profits are discounted at rate $\delta^{+} \in(0,1)$ per period and past losses are discounted at rate $\delta^{-} \in(0,1)$. These two discount rates capture the horizon limits for tax-loss carry forward and tax-loss carry back provisions in the tax code. In particular, $\delta^{+}$captures how far in time current losses can be carried back against past tax payments for a rebate, and $\delta^{-} \in(0,1)$ captures for how long past losses can be carried forward for deductions against subsequent tax obligations..$^{10}$ A firm is allowed a carry over loss deduction against current profits if $s<0$, i.e. if the discounted sum of past incomes is negative on the net, or a carry back tax rebate for current losses if $s>0$. If $s+\pi^{b}<0$, then current profits are not large enough to use up all of the available tax-loss deductions. The remainder is carried forward to the next period at the discount rate $\delta^{-}$. Symmetrically, if $s+\pi^{b} \geq 0$, then the firm has net (cumulative) income that can later be called upon to obtain a tax rebate should the firm run losses in the future. The discount rate $\delta^{+}$is applied in such situations. It is implicit in our formulation that any tax gains arising from past losses or profits are claimed immediately to the extent allowed by the tax code. We describe the determination of tax obligations in detail in the next subsection.

\footnotetext{
${ }^{10}$ The carry back and carry forward limits in the actual tax code are expressed in years, implying zero discounting until the limit is reached followed by full discounting thereafter. Explicitly modelling the current structure, however, is computationally costly. Therefore, we opt out for geometric discounting of allowances. Below, we calibrate the discount rates such that the average duration of carry forward and carry back provisions in the model match those prescribed by the tax code.
} 
Table 3: Tax Obligations

\begin{tabular}{c|cc}
$T\left(\pi^{b}, s\right)$ & $\pi^{b}>0$ & $\pi^{b} \leq 0$ \\
\hline$s>0$ & $\tau \cdot \pi^{b}$ & $-\tau \cdot \min \left\{-\pi^{b}, s\right\}$ \\
$s<0$ & $\tau \cdot \max \left\{\pi^{b}+s, 0\right\}$ & 0
\end{tabular}

Note.- Table shows the net tax position as a function of current net operating income, $\pi^{b}$, and the stock of past net income, $s$.

\subsection{Tax Obligations}

A firm's tax obligations depend on the statutory tax rate, $\tau$, levied on the taxable net operating income whenever it is positive. Taxable income is determined by eligible deductions permitted by past losses. Firms do not have any tax liabilities if their current income is negative, but may be eligible for a tax rebate for past liabilities.

Specifically, there are four cases to consider depending on the signs of current income, $\pi^{b}$, and past net income, $s$. The resulting tax obligations in each case are summarized in Table 3 . The simplest case is a firm that currently runs a loss, $\pi^{b}<0$, and that has experienced losses in the recent past, $s<0$. This firm has no tax liabilities. Another simple case is a firm that generates a profit, $\pi^{b}>0$ with a history of profits $s>0$. Such a firm is not allowed any deductions and therefore pays taxes on the full net income amount for that year, i.e. on $\pi^{b}$. If, instead, this firm has a stock of past losses $(s<0)$, it is allowed to deduct them from its current income. Its taxable income is therefore given by the maximum of $\pi^{b}+s$ and 0 . Finally, if the firm has a stock of past profits and runs a current loss, it is entitled to a tax rebate on past tax payments for a total of $\tau \min \left\{-\pi^{b}, s\right\}$.

Note that the marginal tax rate takes on two values, $T_{\pi} \in\{0, \tau\}$, and that tax obligations depend on $s$ in a non-trivial way. When $s<0$, tax obligations are non-decreasing in $s$, i.e. $T_{s} \in\{0, \tau\}$, because a higher level of $s$ can lead to a smaller tax deduction against current profits. When $s>0$, however, tax obligations are non-increasing in $s$, i.e. $T_{s} \in\{-\tau, 0\}$, because higher values of $s$ entitle the firm to larger tax rebates when net income is sufficiently negative. From the firm's perspective, extreme values of $s$ are preferable to a value of zero, which does not provide any tax advantage. This will be crucial when we analyze the impact of loss-offset provisions on investment behavior in the next section. 


\subsection{Entrant's Problem}

A potential entrant starts its operations if the value of entry exceeds the entry cost: $V^{e} \geq p c_{e}$. The value of entry is:

$$
V^{e}=\int V\left(\varepsilon_{0}, s_{0}\right) d H_{0}\left(\varepsilon_{0}\right)
$$

This formulation implies that upon paying $c_{e}$, entrants' productivity is revealed and they invest in capital for the subsequent production cycle. They are not allowed to exit immediately. The entry costs reflect in part the time or effort cost of identifying a business idea, a product, a target market as well as red tape costs among other things. We assume that these costs are not deductible from future income when the business becomes operational and set $s_{0}=0.11$

\subsection{Distribution of Firms}

Denote the distribution of incumbent firms defined over the space of productivity and past income records by $\Gamma$. To describe the evolution of $\Gamma$ over time due to entry, exit and productivity shocks, define $\mathcal{B}(\mathcal{S})=\left\{(s, \varepsilon): s^{\prime}(k(\varepsilon, s), \varepsilon, s) \in \mathcal{S}\right\}$ for all Borel sets $\mathcal{S} \subset \mathcal{R}$. Similarly, for sets $\mathcal{E} \times \mathcal{S} \subset \mathcal{R}_{+} \times \mathcal{R}$, the measure of entrants is given by:

$$
\mathbf{M}(\mathcal{E}, \mathcal{S})=M \int_{\mathcal{E}} d H_{0}(\varepsilon) \text { if } s_{0} \in \mathcal{S}, \text { and } 0 \text { otherwise. }
$$

With these definitions, the evolution of the distribution of firms is described as follows.

$$
\Gamma^{\prime}(\mathcal{E}, \mathcal{S})=\int_{\mathcal{E}} \int_{B(\mathcal{S})}(1-x(s, \varepsilon)) d \boldsymbol{\Gamma}(\varepsilon, s) d H\left(\varepsilon^{\prime} \mid \varepsilon\right)+\mathbf{M}(\mathcal{E}, \mathcal{S})
$$

\subsection{Households}

The representative household exogenously supplies one unit of labor and derives utility from consumption, which equals total disposable income, given by labor earnings, dividends, and transfers from the government:

$$
p c=w+d+T^{h} .
$$

\footnotetext{
${ }^{11}$ In our simulations, we allowed for varying degrees of deductibility of entry costs, and found its effect on aggregate outcomes to be small, mainly because entrants represent a small segment of the overall economy in any given period.
} 


\subsection{Competitive Equilibrium}

A stationary recursive competitive equilibrium consists of value functions $V(\varepsilon, s), V^{c}(\varepsilon, s), V^{x}$ and $V^{e}$, policy functions $k(\varepsilon, s), n(\varepsilon, s)$ and $x(\varepsilon, s)$, a price level $p$, a measure of incumbent firms $\Gamma(\varepsilon, s)$ and a measure of entrants $\mathbf{M}$ such that:

1. $V(\varepsilon, s), V^{c}(\varepsilon, s), V^{x}, k(\varepsilon, s), n(\varepsilon, s)$ and $x(\varepsilon, s)$ solve the incumbent firm's problem.

2. The free entry condition holds: $V^{e}=p c_{e}$

3. The labor market clears at $w: \int n(\varepsilon, s) d \boldsymbol{\Gamma}=1$

4. The financial market clears: $d=\int \pi^{a}(\varepsilon, s) d \Gamma$

5. Government budget is balanced: $T^{h}=\int T(\varepsilon, s) d \boldsymbol{\Gamma}$

6. The distribution of incumbent firms is stationary: $\Gamma^{\prime}=\Gamma$.

\section{Investment under Corporate Taxation}

In this section we characterize the investment behavior of firms and show how it is affected by the presence of corporate taxation and loss-offset provisions. To see the different channels through which corporate taxation affects investment, consider the heuristic first order condition for the investment decision of the program described by equations (4)-(6). While this condition is not accurate when the objective function is not differentiable at kinks imposed by the tax rules, it nevertheless highlights the main channels through which taxation affects investment. The function arguments are omitted for brevity and subscripts denote partial derivatives.

$$
\mathbb{E}\left[\pi_{k}^{b}\left(1-T_{\pi}\left(\pi^{b}, s\right)\right)+V_{s} \frac{d s^{\prime}}{d k}\right]=p \frac{1-\rho}{\rho}
$$

The right hand side of (9) represents the rental cost of capital. The left hand side summarizes the expected marginal return to investment. At the margin, each unit of investment raises pre-tax net income by $\pi_{k}^{b}$, of which a fraction $T_{\pi}\left(\pi^{b}, s\right)$ is withheld in taxes. The last term denotes the option value of expected tax deductions or rebates that will be carried over into the future.

From (6) we have that $\frac{d s^{\prime}}{d k}=\left(1-\delta^{ \pm}\right) \pi_{k}$, depending on whether $\pi^{b}+s$ is positive or negative. The term $\pi_{k}^{b}=p f^{\prime}(k)-p \delta$ from (3). Rearranging the heuristic first order condition yields the following optimality condition for investment:

$$
f^{\prime}(k)=\frac{1-\rho}{\rho \mathbb{E}[x]}+\frac{\mathbb{E}[\delta \cdot x]}{\mathbb{E}[x]},
$$


where $x \equiv\left(1-T_{\pi}\left(\pi^{b}(k, \varepsilon, \delta), s\right)-\frac{1-\delta^{ \pm}}{p} V_{s}\left(\varepsilon^{\prime}, s^{\prime}\right)\right)$ denotes the effective net-of-tax rate on investment.

The optimal level of investment equates the marginal product of capital to its user cost, which is the sum of the effective rates of interest and depreciation. When there is no taxation, $T_{\pi}=0$ and $V_{s}=0$, hence, $x=1$. The user cost of capital is then simply the expected depreciation rate plus the market rate of interest: $(1-\rho) / \rho+\mathbb{E}[\delta]$. With taxation, the expected net-of-tax rate becomes less than one, and effectively raises the interest rate on capital. When depreciation is stochastic it also creates the second covariance term, which is positive because a larger depreciation shock implies a potential loss, absolving the firm of tax payments. This further raises the cost of capital.

Generally, the net-of-tax rate is determined by the level of current profits, past performance, s, as well as the option value of future tax deductions. All of these components are specific to a firm, hence the heterogeneity in marginal tax rates. Next, we analyze the implications of the different components of $x$ in detail.

\subsection{Distortions from profit taxation}

The first distortion to investment is the taxation of net income. To see this, consider corporate taxation without loss-offset provisions and assume that depreciation rate is fixed. ${ }^{12}$ The marginal tax rate $T_{\pi}$ takes a value of $\tau>0$ if net income is positive and equals zero otherwise, while $V_{s}=0$. This creates a kink in the firm's investment choice. The result is formalized by the following proposition. The proof is relegated to the Appendix.

Proposition 1. In the absence of loss-offset provisions and depreciation shocks, there exist two profitability thresholds, $\underline{\chi}$ and $\bar{\chi}$, defined by

$$
\underline{\chi}=\left(\frac{c_{f}}{\left(\frac{\phi}{r}\right)^{\frac{\phi}{1-\phi}}-\delta\left(\frac{\phi}{r}\right)^{\frac{1}{1-\phi}}}\right)^{1-\phi} \quad \text { and } \quad \bar{\chi}=\left(\frac{c_{f}}{\left(\frac{\phi}{r_{\tau}}\right)^{\frac{\phi}{1-\phi}}-\delta\left(\frac{\phi}{r_{\tau}}\right)^{\frac{1}{1-\phi}}}\right)^{1-\phi}
$$

with $r \equiv \frac{1-\rho}{\rho}+\delta$ and $r_{\tau} \equiv \frac{1-\rho}{\rho(1-\tau)}+\delta$, such that $\left.i\right)$ firms with $\chi<\underline{\chi}$ face an undistorted user cost of capital $r$, make negative profits, and pay no corporate income tax, ii) firms with $\chi>\bar{\chi}$ make positive profits, face a user cost of capital $r_{\tau}>r$, and pay corporate income tax, and iii) firms with $\underline{\chi} \geq \chi \leq \bar{\chi}$ choose investment in order to make zero profits and pay no corporate income tax.

For a firm with a low profitability level $\chi<\underline{\chi}$, maximal profits are not large enough to cover the fixed cost of operation. Therefore, taxable income is negative no matter what the investment

\footnotetext{
${ }^{12}$ This does not qualitatively alter our conclusions.
} 
choice of the firm is. The firm, therefore, is not subject to taxes and investment choice is set at the undistorted level, $k_{\tau=0}=\left(\frac{\chi \phi}{r}\right)^{\frac{1}{1-\phi}}$, where $r$ is the user cost of capital. A firm with a high profitability level, $\chi>\bar{\chi}$, chooses investment so as to equate the marginal product of capital to $r_{\tau}>r$, the effective cost of capital increased by the tax rate $\tau$.

Firms with intermediate levels of profitability, $\chi \in(\underline{\chi}, \bar{\chi})$, are in a situation where investment would optimally be positive in the absence of taxes, but is not, because the after-tax marginal return is below the marginal cost. This situation is depicted in Figure 4. The dash-dotted blue line shows the firm's objective function if taxes were zero. The corresponding optimal capital choice would be $k_{\tau=0}$. The dashed red line shows the objective function if taxes were always positive, independently of net income. The associated capital choice would be $k_{\tau>0}<k_{\tau=0}{ }^{13}$ The firm's true objective function is given in solid by the overlap of the dashed curves, because the firm only pays taxes if it generates profits.

Figure 4: Choice of Capital under Corporate Taxation

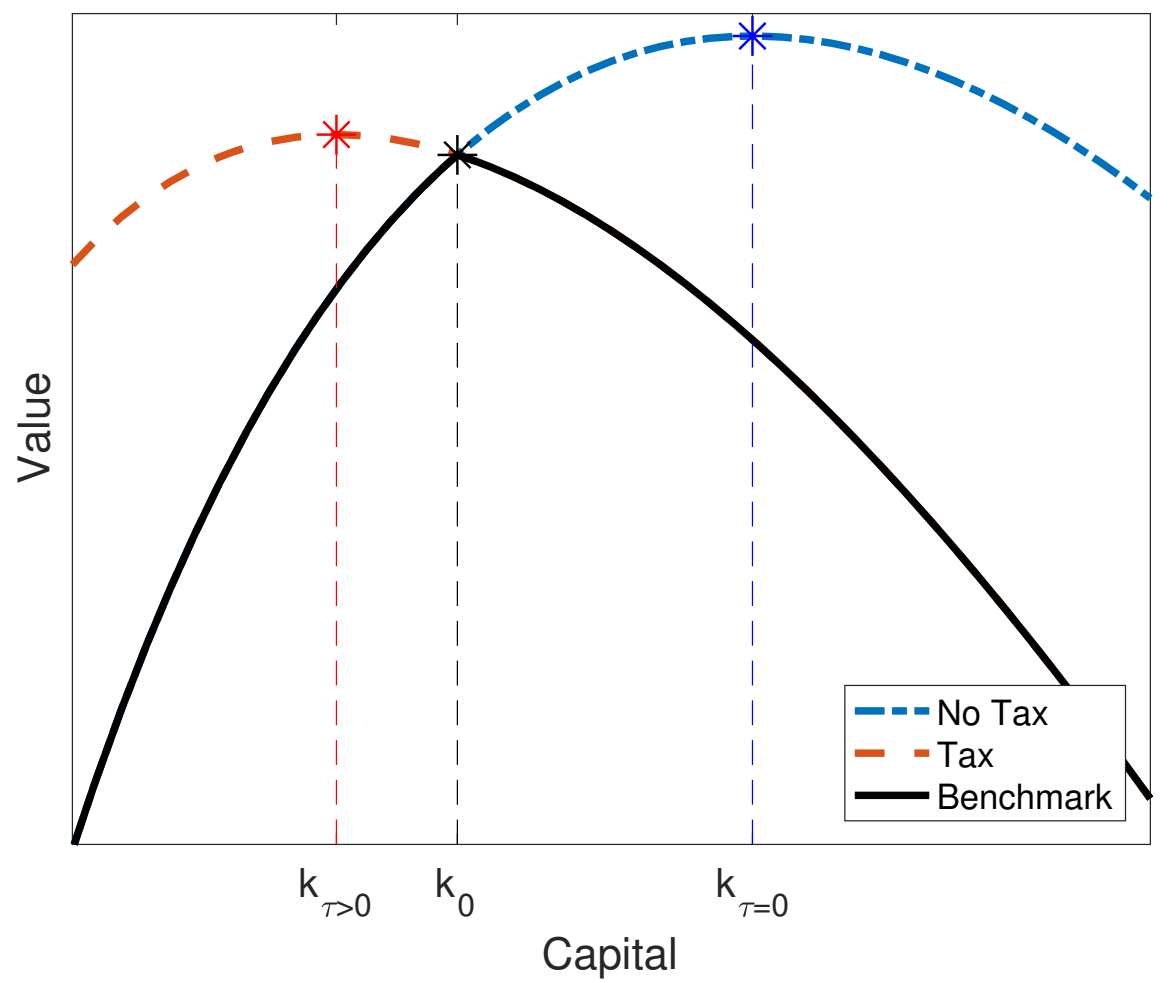

Note.- Figure shows net income as a function of investment for a medium productivity firm in an economy with taxation of (net) corporate income without provisions for loss-offset (solid line).

For the case shown here, optimal investment is $k_{0}$ and profits are exactly zero. ${ }^{14}$ Were the firm

\footnotetext{
${ }^{13}$ At the point $k_{\tau>0}$ in Figure 4 the firm makes a loss and receives a tax credit at the rate of $\tau$.

${ }^{14}$ The level of capital $k_{0}$ is implicitly defined by $\pi^{b}\left(k_{0}, \chi\right)=\chi k_{0}^{\phi}-p \delta k_{0}-p c_{f}=0$.
} 
to increase capital, the marginal return would discontinuously drop the moment the firm started making a taxable profit. Clawing back investment then becomes beneficial until additional investment is profitable enough to make up for the tax rate.

The distortions from profit taxation imply that that capital-labor ratios become a function of productivity. Firms with low productivity levels have optimal capital-labor ratios, while firms with high productivity levels underinvest in capital. For firms with $\chi \in(\underline{\chi}, \bar{\chi})$ the capital-labor ratio declines with productivity. This implies a misallocation of capital towards less productive, and, hence smaller firms.

\subsection{Distortions from loss-offset provisions}

Loss-offset provisions add another set of distortions to capital investment by changing the marginal tax rate on investment based on the history of a firm's performance, i.e. $T_{\pi s} \neq 0$ in (10). Because firm productivity is persistent over time, current productivity is positively correlated with a firm's past profits, captured by the state variable $s$. A direct consequence of this is that large, productive firms are on average unable to claim tax deductions because they have accumulated a positive stock of $s$ over time. On the other hand, smaller, less productive firms, may have accumulated a stock of negative past profits. This lowers their marginal tax rate in the event they generate profits. The existence of loss-offset provisions thus exacerbates the correlation between firm productivity and tax payments highlighted in Section 4.1 .

In addition, through its effect on net income, a firm's investment choice determines the size of potential future tax deductions or rebates. This "dynamic tax optimization incentive" represents a strategic consideration on the part of the firm in order to dynamically optimize exposure to corporate taxes. The presence of $\left.V_{s}\left(\varepsilon^{\prime}, s^{\prime}\right)\right)$ in (10) changes a firm's effective user cost of capital, leading to distortions in the firm's optimal capital investment. The following proposition characterizes optimal investment relative to the economy in Section 4.1 without loss-offset provisions (see appendix for derivations).

Proposition 2. For a given level of profitability $\chi$ there exist thresholds levels $s_{L}$ and $s_{H}$, such that relative to a situation without loss-offset provisions $i$ ) firms with $s<s_{L}$ under-invest, ii) firms with $s>s_{H}$ over-invest, and iii) firms with $s_{L} \leq s \leq s_{H}$ choose capital such that $\pi^{b}+s=0$.

The cutoffs are shown in Figure 5, which presents the firm's choice of capital investment as a function of its tax status $s$ for a fixed level of productivity. The solid blue line shows the capital choice in the benchmark economy where all distortions are present. The dashed red line shows the optimal capital choice if we rule out the dynamic tax optimization incentive 15

\footnotetext{
${ }^{15}$ We calculate the optimal capital choice without dynamic tax optimization as follows. First, we take as given the
} 
Figure 5: Choice of Capital under Corporate Taxation with Carry Overs

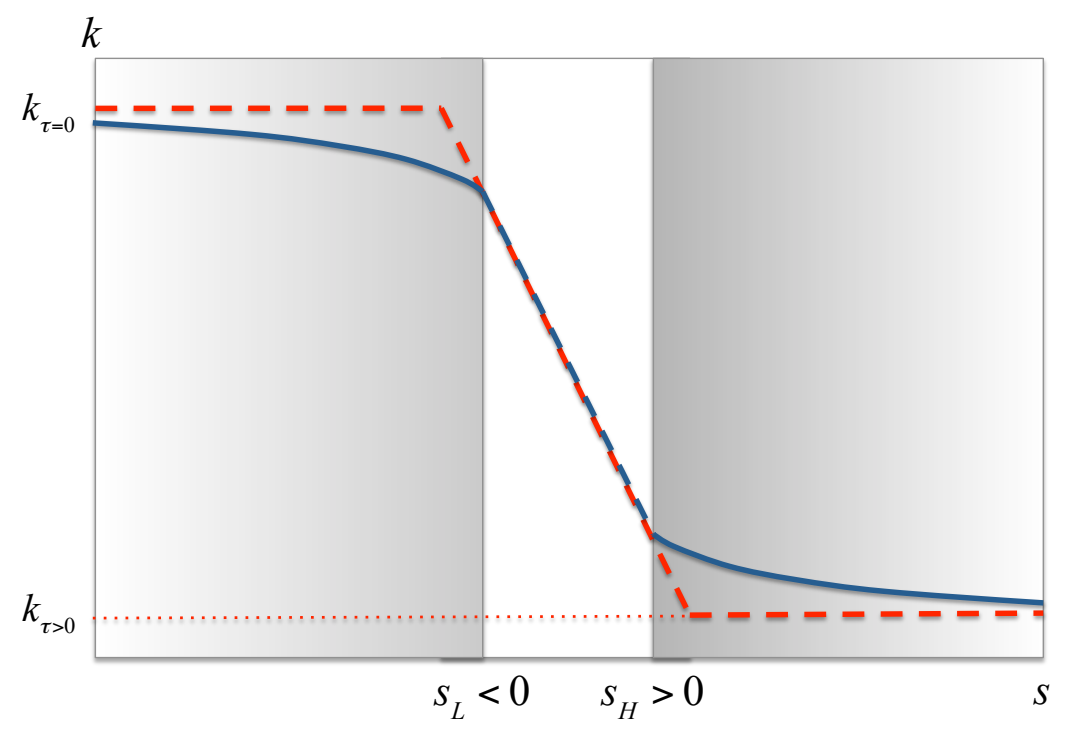

Note.- The figure shows the optimal investment (solid) as a function of tax status for an economy with loss-offset provisions. Negative values of $s$ indicate accumulated loss-carry forward deductions, and positive values represent loss-carry back rebates. The dashed line ignores dynamic tax optimisation effects.

Consider first the dashed red line, which sets $V_{s}=0$. Similar to the case we showed in Section 4.1. the optimal capital choice depends on whether the firm is paying taxes or not. In the left shaded area $s<s_{L}$ and the firm's taxable income is $\pi^{b}+s<0$, implying an optimal choice of capital $k_{\tau=0}$. In the right shaded area $s>s_{H}$, the firm faces a marginal tax rate of $\tau$ because $\pi^{b}+s>0$, and the capital choice is $k_{\tau>0}<k_{\tau=0}$. For intermediate levels $s_{L} \leq s \leq s_{H}$ the firm chooses capital $k_{0}$ such that $\pi^{b}+s=0$. The capital decision $k_{0}$ is determined by the kink created by the presence of the corporate income tax.

The blue solid line incorporates the dynamic tax optimization incentive. The effect of $s$ on investment crucially depends on the degree to which future tax deductions or rebates $s^{\prime}$ change the probability of being taxed. For example, very large negative values of $s$ imply the firm will be tax-exempt in the future, independently of the current capital choice. For this reason, investment approaches the same level as without dynamic tax optimization when the absolute value of $s$ grows. A smaller absolute value of $s$ implies a larger importance of the current capital choice for $s^{\prime}$ and the value of $V_{s}$ in $10 \mathrm{~b}$ becomes larger. From Table 3 it follows that the sign of $V_{s}$ is non-negative when $s<0$ and non-positive when $s>0$.

optimal investment policy $k(\varepsilon, s)$ from the benchmark model. Then, for a given state $(\varepsilon, s)$, we hold the level of $s^{\prime}$ implied by the benchmark optimal capital choice fixed at $\tilde{s}=s^{\prime}(k(\varepsilon, s), \varepsilon, s)$. Given $\tilde{s}$ we let the firm choose the optimal value of $k$ again. This implies that the choice of $k$ has no impact on $s^{\prime}$, i.e. $\frac{d s^{\prime}}{d k}=0$ in 9 . 


\subsection{Distortions to firm survival}

The last distortion we study is to a firm's decision to remain in business. Firms with an accumulated stock of tax discounts may afford to stay in business, even when it is socially optimal for them to exit the industry. This inhibits a productivity-enhancing turnover of businesses based on their productivity alone and leads to a deterioration of firm quality in the industry.

Figure 6: Mis-Selection under Corporate Taxation with Carry Overs

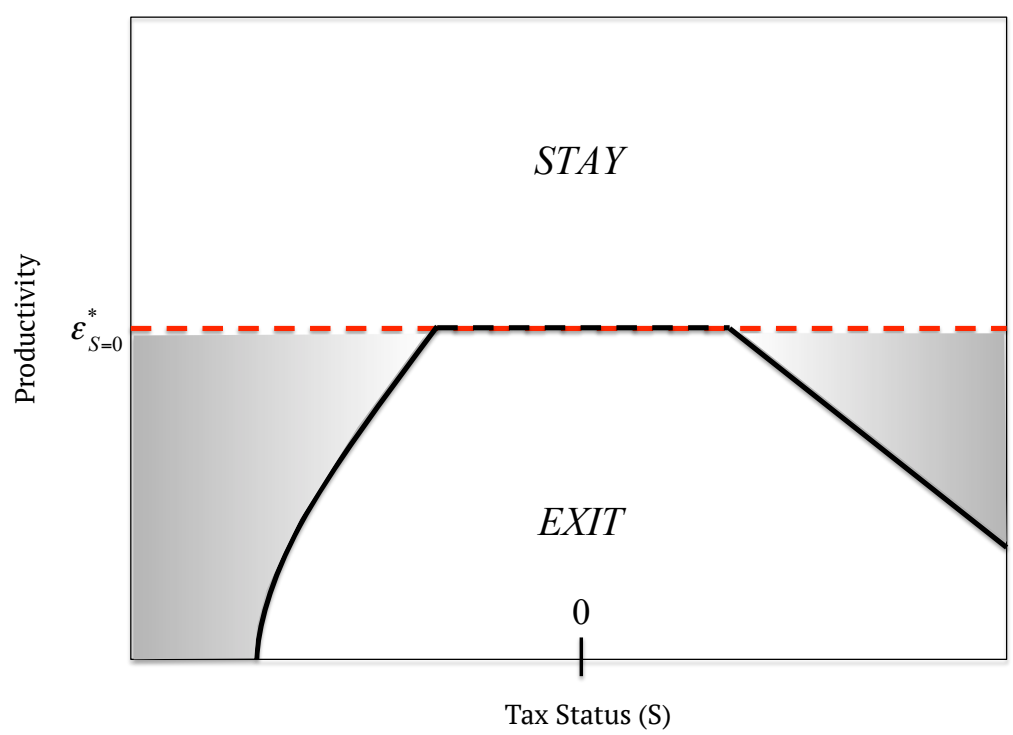

Note.- Figure shows the critical productivity levels for remaining in business as a function of tax advantages in an economy with (solid) and without (dash) loss-offset provisions in the corporate tax system. Negative values of $s$ indicate accumulated loss carry forward deductions, and positive values represent loss carry back rebates. The shaded area represents the misallocative effects of loss-offset on industry turnover.

Figure 6 depicts the productivity cutoffs as a function of the stock of past profits. The red dashed line shows the cutoff level $\varepsilon_{s=0}^{*}$ for an economy without provisions for loss-offsets. When firms cannot use carry overs to affect their marginal tax rate, the cutoff does not depend on $s$ and is given by a horizontal line. Firms with productivity below the line exit, whereas those above remain operative. The black solid line shows the cutoffs in our benchmark economy with loss-offset. The shaded gray areas indicate firms with productivity levels that would have normally induced them to exit the industry, but choose to remain in business because of tax advantages. Two types of firms make up this group: those with a large negative value of $s$, who expect a tax break if they make profits in the future, and, those with large positive values of $s$, who expect tax rebates on past payments should they run losses. 


\section{Model Calibration and the Benchmark US Economy}

We preset some of the parameters based on prior information, and jointly calibrate the remaining parameters to match the key properties of the corporate sector in the US regarding net income and taxes paid.

A model period corresponds to one year. The discount rate is set to $\rho=0.96$ implying a real interest rate of 4 percent per annum. The return-to-scale parameter is set to $\gamma=0.85$. The payroll share in production is set to $\beta=0.56=0.85 \cdot 2 / 3$, implying $\alpha=0.29$. We normalize the wage rate to 1 .

Firm productivity $\varepsilon$ has a $\log$-normal distribution with mean $\mu_{\varepsilon}$, standard deviation $\sigma_{\varepsilon}$, and persistence $\rho_{\varepsilon}$. Because the mean cannot be identified independently from the price level $p$, we normalize $\mu_{\varepsilon}$ to zero, implying a median productivity of 1 . Using the sample of firms in Compustat, we estimate the persistence of firm level productivity to be 0.84 and set $\rho_{\varepsilon}$ accordingly.

Capital depreciation is given by $\delta=\delta_{0} e^{\delta_{1} \omega}$, where the random component, $\omega$, is independently and identically distributed with a standard normal density. In the calibration of the model we target an average depreciation rate of 0.08 .

The statutory tax rate, $\tau$, is set to $35 \%$. Ignoring exceptions and special provisions, the current tax code generally allows businesses to write-off losses for 20 years forward and 2 years back. Accordingly, we set $\delta^{+}=0.5$ and $\delta^{-}=0.05$. Table 4 summarizes the preset parameters.

Table 4: Calibration Summary: Preset Parameters

\begin{tabular}{ccl}
\hline Parameter & Value & Target \\
\hline$\beta$ & 0.56 & Payroll share \\
$\gamma$ & 0.85 & Profit share \\
$\rho$ & 0.96 & Real rate of return $r=4 \%$ \\
$\delta^{-}$ & 0.05 & 20 yr. loss carry forward time limit \\
$\delta^{+}$ & 0.50 & 2 yr. loss carry back time limit \\
$\rho_{\varepsilon}$ & 0.84 & Persistence of firm-level TFP \\
$\tau$ & 0.35 & Statutory corporate tax rate \\
$w$ & 1.00 & Normalization \\
\hline
\end{tabular}

The remaining parameters are the entry cost, $c_{e}$, the fixed cost of operation $c_{f}$, the standard deviation of innovations to the productivity process $\sigma_{\varepsilon}$, and the two parameters describing the stochastic depreciation process, $\delta_{0}$ and $\delta_{1}$. We calibrate these parameters jointly so that the model generates realistic distributions of net income and tax deductions.

The target moments come from a variety of sources. The objective is to capture the process 
of net income and the total size of the loss-offset provisions used against tax liabilities in the data. While there is no one-to-one mapping between parameters and moments, we argue that the moments we choose are informative about the underlying parameters. First, we target an entry (and exit) rate of $10 \%$. This is informative about the fixed operating cost $c_{f}$. According to IRS records on corporate income tax returns, $49 \%$ of the returns reported negative net income in $2013 .{ }^{16}$ Of the remaining $51 \%$ of returns with positive net income, only $33 \%$ actually paid taxes after statutory special deductions. ${ }^{17}$ The resulting total income subject to tax is $85 \%$ of total net income before deductions. This is a key moment because it is informative about the extent to which profitable firms make use of tax deductions.

A summary of model parameters along with the calibration targets are reported in Table 5 .

Table 5: Calibration Summary: Jointly Calibrated Parameters

\begin{tabular}{cclcc}
\hline Parameter & Value & Target & Data & Model \\
\hline$c_{e}$ & 93.31 & Entry \& exit rate & 0.10 & 0.10 \\
$c_{f}$ & 19.63 & Fraction of firms with $\pi^{b}<0$ & 0.49 & 0.49 \\
$\sigma_{\varepsilon}$ & 0.17 & Fraction of firms paying taxes & 0.33 & 0.37 \\
$\delta_{0}$ & 0.0002 & Fraction of net income taxed & 0.85 & 0.85 \\
$\delta_{1}$ & -8.62 & Average depreciation rate & 0.08 & 0.08 \\
\hline
\end{tabular}

The model generally matches the moments in the data very well, albeit imperfectly due to functional form assumptions on the distributions of stochastic variables. The entry \& exit rate, average depreciation, and the amount of deductions implied by loss-offset provisions are very close to their data counterparts. The average marginal tax rate in the benchmark economy is $18.0 \%$. Among the universe of corporations this number is $18.6 \%$, as estimated by the Congressional Budget Office (CBO, 2017), while it was $11.8 \%$ in our sample of publicly listed firms in 2013. The model thus generates a number in the range of the estimates in the data even though this moment was not directly targeted.

Endogenous firm exit results in a skewed distribution of productivity, which, in turn, results in a concentrated distribution of firm size. For instance, the share of the largest $44 \%$ of firms in employment is 0.94 in the model, compared to 0.95 in the 2014 Census data.

Stochastic depreciation enables the model to capture the relationship between firm size and loss incidence. While on aggregate, roughly half of firms are making a loss, this number falls to $7 \%$ for the largest third of firms in terms of employment. We estimate the corresponding figure to be $14 \%$ in Compustat. The fact that large firms can make losses is an important property of the

\footnotetext{
${ }^{16}$ The figures are taken from Table 18 of $\overline{I R S}(2013)$.

${ }^{17} 92 \%$ of these deductions in value are comprised of net operating loss deductions
} 
model which is crucial for matching the moments presented in Table 5, The calibration implies a ratio of average losses to average profits of 0.36 , compared to 0.24 in the data. The combination of persistent productivity and stochastic shocks to income leads to a persistent process for corporate income, with an $\mathrm{AR}(1)$ coefficient of 0.60 . We estimate the corresponding figure to be 0.67 in Compustat. ${ }^{18}$ The fact that the model captures the key moments of income, tax and productivity distributions in the economy is reassuring of its predictions for counterfactual tax reforms we analyze below.

The firm-specific investment wedges are summarized in Panel (a) of Figure 7, which shows the average marginal tax rate by productivity and tax status for incumbent firms. ${ }^{19}$ Lighter colors represent a higher average marginal tax rate, which is computed by averaging over the possible realizations of the depreciation shock for each state $(\varepsilon, s)$. For any given productivity level, differences in past income performance create heterogeneity in marginal tax rates across firms. Those with superior past performance (high $s$ ) typically pay higher tax rates on the margin, while there is a large number of states in which marginal taxes are zero. The figure also shows that for firms with higher productivity, the depreciation shock is relatively more important in determining whether net income is positive or not. ${ }^{20}$ For low productivity firms, the fixed cost component is relatively more important.

Panel (b) shows the distribution of incumbent firms by productivity and past performance. The red dashed line shows the exit threshold. Firms that lie below the line exit prior to the next investment cycle. Note that firms in the right region, implying profits in the recent past, pay substantially higher MTR's and are somewhat more productive than those in the left region. Furthermore, the left region is situated where productivity and taxes are positively correlated ( $c f$. Panel (a)). These patterns suggest that the misallocative effects of the tax system are potentially large.

Next, we evaluate the implications of the heterogeneity in marginal tax rates for aggregate output and productivity.

\section{Productivity and Output Gains from Tax Reform}

In this section, we use the benchmark model to simulate a number of policy reforms. In each case, we compute the long-run stationary equilibrium associated with the new tax policy and compare it with the benchmark economy. All economies have the same quantity of labor, as labor is inelastically supplied by a unit measure of households. The quantity of capital, however, potentially

\footnotetext{
${ }^{18}$ Specifically, since income can take negative values, we estimate a first-order autoregressive process for $y=$ $\operatorname{sign}(\pi) \log (|1+\pi|)$ controlling for industry and year fixed effects.

${ }^{19}$ Because $s$ can take negative values, we use the modified $\log$ arithm, where $\log s=\operatorname{sign}(s) \cdot \log (1+|s|)$.

${ }^{20}$ This is due to the fact that depreciation shocks are linear in $k$, while the production function is concave in $k$.
} 
Figure 7: Marginal Tax Rates and Firm Distribution

(a) Average Marginal Tax Rate

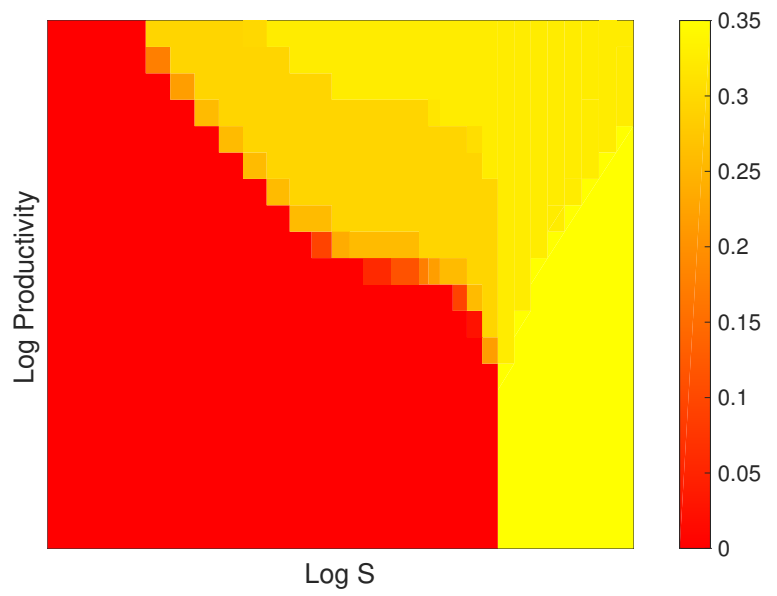

(b) Marginal Density Map

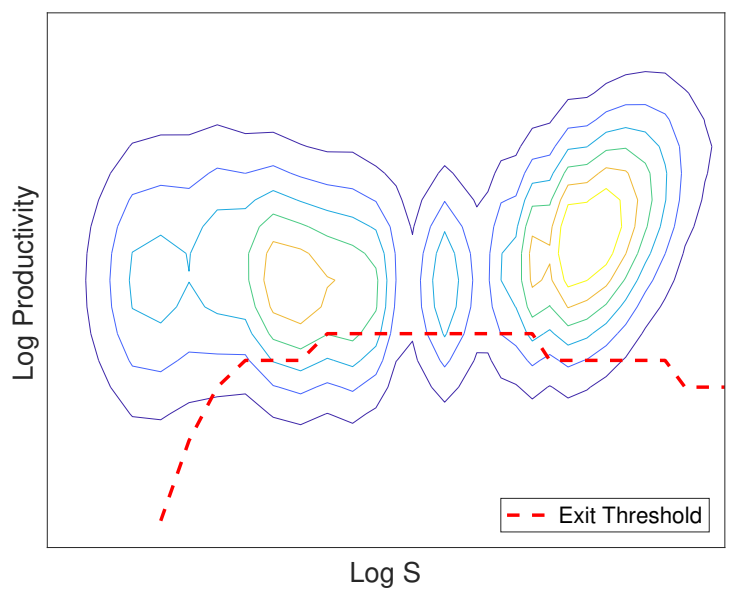

Note.- Figure shows a heat map of marginal tax rates (left) and a contour map of the distribution of firms (right) by productivity $(\log \varepsilon)$ and past performance (modified $\log s=\operatorname{sign}(s) \cdot \log (1+|s|)$ ). Firms below the red dashed line in Panel (b) exit prior to the next investment cycle.

varies due to the investment response to the tax reforms. Unless otherwise noted, the statutory tax rates are adjusted so that the tax reforms are revenue-neutral.

We consider three main policy reforms in particular. The first tax reform eliminates the lossoffset provisions, but maintains the tax on corporate income. The second reform replaces the corporate tax system with a tax on value added. The third reform replaces the carry over rules with full loss-offset, where firms are contemporaneously subsidized for their losses. An analysis of selectively eliminating carry-forward and carry-back provisions is provided in the Appendix.

\subsection{Eliminating loss-offset provisions}

Consider first the elimination of loss-offset provisions. A firm's tax base is now given by its current net income $\pi^{b}(k, \varepsilon, \delta)$ alone, and, hence, her tax liabilities are given simply by $\max \left\{\tau \pi^{b}, 0\right\}$. For a given corporate tax rate, eliminating loss-offset provisions increases the total tax liabilities of the industry and raises the fraction of firms paying taxes. The additional revenue allows the government to reduce the statutory corporate tax rate by roughly eight percentage points to 26.6 percent without sacrificing revenue. The average marginal tax falls to 16 percent. This particularly benefits productive firms who have less to gain from loss provisions and generally pay the full statutory rate on profits. Less productive firms that run occasional losses pay taxes more often now, albeit at the reduced rate. The distribution of capital (and hence labor) shifts towards more productive and larger firms as a result, which stimulates aggregate investment. 
The new economy is also more efficient. The dispersion in (value-added weighted) marginal products of capital falls and average TFP of operational firms increases by 1.3 percent. This stems from a better allocation of resources among incumbent firms, as well as a better selection of firms. The lower corporate tax rate attracts entry into the industry, driving up labor demand and raising real wages $w / p$. The higher real wage rate pushes out of the industry less productive firms and firms that previously remained in business only because of government support via loss provisions. This results in an almost two percentage point increase in the exit rate.

The efficiency gains and the lower marginal tax rate increase investment, which raises the aggregate capital stock by 1.8 percent. In the new stationary equilibrium, aggregate output is 1.9 percent higher than in the benchmark economy.

Next, we consider a value-added tax reform, which eliminates any remaining firm-level heterogeneity in effective marginal tax rates.

Table 6: Revenue-neutral Policy Experiments

\begin{tabular}{llcccc}
\hline & & No & Value- & \multicolumn{2}{c}{ Full Loss-Offset } \\
\cline { 5 - 6 } Moment & Benchmark & Loss-Offset & Added Tax & Constant $\tau$ & Revenue-neutral \\
\hline Output $Q^{*}($ real) & 1.00 & 1.02 & 1.14 & 1.05 & 1.00 \\
Average TFP & 1.00 & 1.01 & 1.01 & 0.99 & 0.98 \\
Agg. Capital Demand & 1.00 & 1.02 & 1.34 & 1.13 & 1.01 \\
Agg. Labor Demand & 1.00 & 1.00 & 1.00 & 1.00 & 1.00 \\
Price Level $p$ & 1.00 & 0.98 & 0.95 & 0.95 & 1.00 \\
Firms paying taxes (share) & 0.35 & 0.53 & 1.00 & 0.44 & 0.40 \\
Entry / exit rate & 0.10 & 0.12 & 0.12 & 0.08 & 0.05 \\
Tax Revenue $T^{*} / Q_{\text {bench }}^{*}$ & 0.09 & 0.09 & 0.09 & 0.07 & 0.09 \\
Tax rate $\tau$ & 0.35 & 0.27 & 0.08 & 0.35 & 0.44 \\
Average MTR & 0.18 & 0.16 & 0.08 & 0.35 & 0.44 \\
VA-weighted $\sigma_{M P K}$ & 0.013 & 0.002 & 0 & 0 & 0 \\
\hline
\end{tabular}

Note.- The level of real output, TFP, capital and labor demand, as well as the price level have been normalized to one in the benchmark. The tax revenue is normalized by the level of output in the benchmark economy. For the case of the value-added tax, the tax rate $\tau$ and the average marginal tax rate refer to the revenue-neutral value-added tax. $\sigma_{M P K}$ refers to the value-added weighted standard deviation of marginal products of capital.

\subsection{Value-Added Tax}

There are two key differences between a corporate income tax and a value-added tax. First, revenue (the tax base in our model since intermediates are not explicitly modelled) is always non-negative. This implies that all firms are subject to taxation and tax payments cannot be deferred. Second, 
whereas the burden of the corporate tax falls entirely on capital, thereby distorting capital-labor ratios, the value-added tax divides the tax burden between the two factors, resulting in efficient capital-labor ratios in production. ${ }^{21}$

The third column of Table 6 shows the results of replacing the corporate tax system in the benchmark economy with a VAT that raises the same tax revenue. This requires a tax rate of $7.9 \%$ on value added in the new equilibrium. Average TFP of incumbent firms increases by $1.4 \%$ relative to the benchmark economy. The additional gains come as a result of firms' factor demand now being identically affected by taxation, independently of a firm's level of productivity. All production units now equate marginal returns on capital (and labor), including firms with negative net incomes who are no longer exempt from taxation.

Shifting from a corporate income tax to a VAT significantly reduces the cost of capital for two main reasons. First, the burden of raising tax revenue is shared with labor, which has double the income share in production. Second, improvements in productive efficiency allow the government to set a significantly lower tax rate on value added for a given revenue target.

Together, these changes lead to an increase in capital investment by $33.6 \%$ and a total output gain of $13.9 \%$. Whereas the gains from eliminating loss-offset provisions came mainly from improved TFP, a significant part of the output gains from switching to VAT comes from capital accumulation. In shifting the tax burden from capital to labor, the government relies less on the elastic factor and more on the fixed factor to raise revenue. The shift encourages capital accumulation without distorting employment and amplifies TFP gains and the output response to the tax reform.

\subsection{Full Loss-Offset}

The final reform we consider is full loss offset, where firms are given contemporaneous tax rebates for the losses they incur. Because tax reductions are applied immediately, carry forwards and carry backs are no longer needed. Full loss offset therefore gives rise to a uniform marginal tax on capital. However, because the government is now subsidizing all firms in the event of a loss, the total tax revenue is significantly reduced. Making the policy reform revenue-neutral creates the need to raise the marginal tax rate.

The last two columns of Table 6 show the results from switching to a full loss offset policy. In the column labeled 'Constant $\tau$ ', the statutory tax rate is kept constant, while in the last column a higher tax rate is adopted to maintain revenue neutrality. Switching to full offset with an unchanged tax rate raises output by 5.1 percent. The positive output effects are a result of the complete elimination of cross-sectional heterogeneity in MTR's on capital. On the downside, full offset leads

\footnotetext{
${ }^{21}$ In Appendix B we show the solution to the firm's problem in the case of a value-added tax, where this is shown formally.
} 
to lower capital demand among firms which now always face a marginal tax rate of $\tau$, but were tax-exempt in the benchmark. Because low-productivity firms now receive immediate transfers from the government, their market value increases. In equilibrium this leads to less stringent firm selection and causes a mild drop in average TFP of $0.7 \%$.

Having to subsidize losses reduces overall tax revenue by $18 \%$, in spite of a widened tax base. To make up for the lost revenue, the statutory tax rate has to be raised by 8.5 percentage points to 43.5 percent. This completely undoes the output gains from the full offset policy and is reflected not only in lower capital demand due to higher user costs, but also in lower average TFP.

\subsection{Industry Turnover and TFP Gains}

Distortions to firm exit behavior are an important source of misallocation in our model. A significant fraction of changes in TFP associated with the tax reforms presented above stems from the selection of firms into the industry. In the benchmark economy, some incumbent firms are occasionally profitable firms that remain in business because of tax breaks. Once these advantages are eliminated, productivity is the sole determinant of firm survival, which leads to a more efficient selection of firms.

The mechanics of selection are similar in all experiments. The tax reforms essentially lower the tax burden on capital and raise the after-tax profits in the industry. This encourages growth through the firm entry margin, which puts upwards pressure on the real wage. This in turn pushes up the productivity threshold below which firms exit the industry. Eliminating loss-offset provisions or switching to a VAT raises the entry-exit rate. Under full loss offset this channel is overturned by the fact that unprofitable firms receive immediate government transfers. This increases their survival probability and has negative implications for average TFP, as manifested in the reduced exit rate.

To highlight the relative importance of the selection channel, we re-calibrated the benchmark model assuming a random, exogenous exit rate of $10 \%$ and re-evaluated the effects of the no lossoffset and value added tax reforms described above ${ }^{22}$ The TFP gains from both experiments are significantly smaller in the random exit model varying between $0.2 \%$ and $0.6 \%$. Nonetheless, output gains are significant, albeit smaller. Eliminating loss-offset provisions raises output by $1.0 \%$, whereas switching to VAT raises output by $7.2 \%$. Because the selection margin is absent, these results are now mainly driven by capital accumulation.

\subsection{Debt Financing}

In our benchmark analysis, we assumed that firms finance capital investments through equity issuance alone. When investment is financed by debt instead, the tax burden on capital is lower

\footnotetext{
${ }^{22}$ See Tables 9 and 10 in Appendix $\mathrm{C}$ for detailed results on the calibration and policy experiments.
} 
than suggested by the model since the US tax system allows for the tax deduction of interest payments. Flow of funds data suggests that the leverage ratio for non-financial corporate businesses was $29.3 \%$ for the $1984-2015$ period. In the appendix, we assess the sensitivity of the results to our financing assumption using a version of the model where investment is partially financed by debt, assuming a fixed leverage ration of $29.3 \%$. The implied gains from tax reform is somewhat smaller as a result. Eliminating loss offset provisions result in an output gain of $1.7 \%$, whereas replacing the corporate income tax with a sales tax increases output by $12.3 \%$. The appendix provides the details on the simulations.

\section{Interaction of Taxes with Other Sources of Misallocation}

Our analysis focused on taxes as the only source of misallocation whereas there are plausibly other distortions that can impede an efficient allocation of capital, such as adjustment costs or credit constraints. Whether these impediments mitigate or exacerbate the findings here depends on how they interact with taxes. To see this, consider the usual optimality condition for investment expressed in logs,

$$
m p k=t a x+m c,
$$

where $m p k$ is the (log) marginal product of capital and $m c$ is the $(\log )$ marginal cost of investment. $\operatorname{tax}=\log (1 / \mathbb{E}[x])$ denotes the tax component of the marginal cost, and is decreasing in the netof-tax rate $x$. Dispersion in $m p k$ across firms could arise either from variations in tax as we argue here, or from variations in $m c$. Using the cross-sectional variance of $m p k$ as a measure of misallocation, define the marginal impact of the variation in tax on misallocation as:

$$
\frac{\partial \sigma_{m p k}^{2}}{\partial \sigma_{t a x}}=2\left[\sigma_{t a x}+\rho_{t a x, m c} \sigma_{m c}\right]
$$

where $\rho_{t a x, m c}$ is the correlation coefficient between $\operatorname{tax}$ and other components of marginal cost ${ }^{23}$ With additional variation in marginal costs among firms, the distortionary effect of tax heterogeneity can be mitigated (exacerbated) if $m c$ is correlated negatively (positively) with firm-specific tax rates. We are interested in measuring the extent to which the presence of $\sigma_{m c}>0$ would affect our findings. This can be assessed by evaluating (11) for $\sigma_{m c}=0$ and $\sigma_{m c}>0$, and taking the ratio:

$$
\left.\frac{\partial \sigma_{m p k}^{2}}{\partial \sigma_{t a x}}\right|_{\sigma_{m c}>0} /\left.\frac{\partial \sigma_{m p k}^{2}}{\partial \sigma_{t a x}}\right|_{\sigma_{m c}=0}=1+\frac{\sigma_{t a x, m c}}{\sigma_{t a x}^{2}}
$$

This ratio represents the rate of amplification (or attenuation) implied by other distortions. A

\footnotetext{
${ }^{23}$ Note that the variance of $m p k$ is equivalent to $\sigma_{m p k}^{2}=\sigma_{m c}^{2}+\sigma_{t a x}^{2}+2 \sigma_{t a x, m c}=\sigma_{m c}^{2}+\sigma_{t a x}^{2}+2 \rho_{t a x, m c} \sigma_{m c} \sigma_{t a x}$.
} 
Table 7: Interaction of Taxes with Other Sources of Misallocation

\begin{tabular}{ccccc}
\hline Dependent Variable: & $\log (q / k)$ & $\log k_{t+1} / k_{t}$ & $i_{t} / k_{t}$ & liquidity \\
\hline $\operatorname{tax}$ & 0.997 & 0.102 & 0.023 & 0.004 \\
& $(0.053)$ & $(0.009)$ & $(0.003)$ & $(0.011)$ \\
\hline
\end{tabular}

Note.- Table shows the OLS coefficients obtained from regressing capital productivity, capital growth, the investment rate and liquidity (current assets over total assets) on the tax component of marginal cost of investment computed as $\log (1 /(1-M T R))$. Data comes from Compustat, 1988 - 2015. Standard errors are clustered at the firm level. See text for details.

ratio below one means that the findings from our model constitute an upper bound on the distortionary effects of corporate taxation. Note that the last term in (12) is the OLS coefficient obtained from regressing mc on tax. When measures of marginal products are available but those of marginal costs are not, then one can use the optimality condition for investment to approximate $m c$ with $\hat{m} c=m p k-t a x$. A coefficient that is statistically zero would indicate that there is no interaction between other components of marginal costs and taxes $\left(\rho_{m c, t a x}=0\right)$. This method is equivalent to regressing mpk on tax and testing if the coefficient is one, which is how we implement it.

To gauge the role of frictions that are not explicitly modelled here, we first regress the marginal product, as proxied by the ratio of output-to-capital stock, on the tax component of marginal cost, $\log (1 /(1-M T R))$, using the marginal tax rate available in our sample. A full interaction of year and industry fixed effects are included as control variables, meaning the estimated coefficient is identified from the cross-sectional variation within an industry. The first column in Table 7 shows the results. The regression coefficient is 0.997 (s.e. 0.527), suggesting that other sources of frictions are uncorrelated with tax distortions. Given the standard error, our findings lie in the \pm 10.5 percent interval 19 out of 20 times.

Next, we use specific proxies for potential heterogeneity in non-tax components of marginal cost, such as capital adjustment costs or financial frictions. ${ }^{24}$ Our proxy for marginal adjustment cost is the growth rate of capital. When adjustment costs are convex, a faster growth of capital is associated with higher marginal cost of investment. A similar association arises in models of credit constraints, where the constrained firms are those that are trying to raise funds to grow. We measure capital growth in two ways, first using $\log k_{t+1} / k_{t}$, and then via the ratio of investment expenditures on plant, property and equipment (PPE) to total assets. Columns (2) and (3) in Table 7 show that these measures depend positively on the tax component of marginal cost, implying that adjustment costs likely amplify the gains from tax harmonization estimated above. A more precise

\footnotetext{
${ }^{24} \mathrm{~A}$ detailed investigation of how taxes may interact with these frictions is beyond the scope of this paper. The goal in this subsection is to give the reader an indication of what one might expect from a more detailed analysis.
} 
assessment is however not possible since we do not know how to translate the growth rate of capital to units of marginal cost. The last column projects liquidity, a proxy for financial constraints, on marginal tax rates. The regression coefficient is statistically not different from zero, implying that liquidity constraints may not affect our estimates of gains from tax reform in a significant way.

\section{Conclusion}

There exists important heterogeneity in marginal tax rates among US corporations. In this paper we showed that the current corporate tax code generates firm-specific effective marginal tax rates which can lead to the misallocation of capital. In a calibrated model we found that eliminating these firm-level differences can lead to significant output gains.

These results stress the importance of firm heterogeneity for the desirability of loss-offset provisions. When there are productivity differences among firms that are likely to persist in the near future, offsetting losses implies a redistribution of resources from more efficient firms to less efficient ones. The resulting distortions are fairly large. At 13.9 percent, the total output gain corresponds to roughly seven years of per capita GDP growth in the post WWII era. Total employment is kept constant in the simulations. Larger gains are possible to the extent that additional investment generated by improved productivity draws more labor into the economy.

The simulations highlight firm entry and survival as important mechanisms through which productivity gains realize. Empirical measurement of the extent of mis-selection and its impact on productivity and investment remain important avenues for future research.

Another result that emerges from the simulations is that the full loss-offset policy may not be not a viable option to improve efficiency. Even though it eliminates the firm-specific distortions to investment, the need for a higher tax rate to maintain revenue neutrality raises the cost of capital relative to labor and results in output losses. Generally, there is no guarantee that full loss offset is even feasible. If losses are sufficiently large in the economy, the government may not be able to raise enough tax revenue from profitable firms to cover the subsidies. 


\section{References}

Adamopoulos, T. And D. Restuccia (2014): “The size distribution of farms and international productivity differences," American Economic Review, 104, 1667-1997.

Altshuler, R. And A. J. Auerbach (1990): “The significance of tax law asymmetries: An empirical investigationz," Quarterly Journal of Economics, 105, 61-86.

Asker, J., A. Collard-Wexler, And J. De Loecker (2014): “Dynamic inputs and resource (mis) allocation," Journal of Political Economy, 122, 1013-1063.

Auerbach, A. J. (1986): “The dynamic effects of tax law asymmetries," Review of Economic Studies, 53, 205-225.

Bils, M., P. J. Klenow, And C. RuAne (2017): “Misallocation or Mismeasurement?” Tech. rep., Working Paper.

Buera, F. J., J. P. Kaboski, And Y. Shin (2011): "Finance and development: A tale of two sectors," The American Economic Review, 101, 1964-2002.

CBO (2017): “International Comparisons of Corporate Income Tax Rates," Tech. Rep. 52419, Congressional Budget Office, www.cbo.gov/publication/52419.

Cummins, J. G., K. A. Hassett, and R. G. Hubbard (1994): "A reconsideration of investment behavior using tax reforms as natural experiments," Brookings papers on economic activity, 1994, 1-74.

David, J. M. And V. Venkateswaran (2017): “Capital Misallocation: Frictions or Distortions?" Tech. rep., NBER.

Domar, E. D. And R. A. Musgrave (1944): "Proportional income taxation and risk-taking," The Quarterly Journal of Economics, 58, 388-422.

Graham, J. R. (1996): "Proxies for the corporate marginal tax rate," Journal of Financial Economics, 42, 187-221.

Graham, J. R., M. L. Lemmon, And J. S. Schallheim (1998): “Debt, Leases, Taxes, and the Endogeneity of Corporate Tax Status," Journal of Finance, 53, 131-162.

GRAHAM, J. R. AND L. F. MiLls (2008): "Using tax return data to simulate corporate marginal tax rates," Journal of Accounting and Economics, 46, 366-388. 
Gravelle, J. (2004): “The Corporate Tax: Where Has It Been and Where Is It Going?” National Tax Journal, 57, 903-923.

Greenwood, J., J. M. Sanchez, And C. Wang (2010): "Financing Development: The Role of Information Costs," American Economic Review, 100, 1875-1891.

Guner, N., G. Ventura, AND Y. XU (2008): "Macroeconomic implications of size-dependent policies," Review of Economic Dynamics, 11, 721-744.

HOPEnhayn, H. AND R. Rogerson (1993): "Job turnover and policy evaluation: A general equilibrium analysis," Journal of Political Economy, 101, 915-938.

HSIEH, C.-T. AND P. J. KLENOW (2009): "Misallocation and manufacturing TFP in China and India," Quarterly Journal of Economics, 124, 1403-1448.

IRS (2013): “Statistics of Income-Corporation Income Tax Returns,” Tech. rep., Internal Revenue Service.

Midrigan, V. AND D. Y. XU (2014): "Finance and misallocation: Evidence from plant-level data," The American Economic Review, 104, 422-458.

Olley, G. S. AND A. PAKes (1996): "The dynamics of productivity in the telecommunications equipment industry," Econometrica, 64, 1263-1297.

RestuCCiA, D. AND R. Rogerson (2008): "Policy distortions and aggregate productivity with heterogeneous establishments," Review of Economic dynamics, 11, 707-720.

- (2017): "The Causes and Costs of Misallocation," Journal of Economic Perspectives, 31, $151-174$.

STIGLITZ, J. E. (1969): “The effects of income, wealth, and capital gains taxation on risk-taking," Quarterly Journal of Economics, 83, 263-283. 


\section{A - Proofs of Propositions}

Proof of Proposition 1: The threshold $\underline{\chi}$ is defined such that firms with $\chi<\underline{\chi}$ make a loss and are not subject to taxation. Hence $k_{\tau=0}=\left(\frac{\phi \chi}{r}\right)^{\frac{1}{1-\phi}}$, with $r=\frac{1-\rho}{\rho}+\delta$. It follows that after-tax income evaluated at $k_{\tau=0}$ is $\underline{\chi}^{\frac{1}{1-\phi}}\left[\left(\frac{\phi}{r}\right)^{\frac{\phi}{1-\phi}}-\delta\left(\frac{\phi}{r}\right)^{\frac{1}{1-\phi}}\right]-c_{f}$. Setting this equal to zero and solving for $\underline{\chi}$ gives the threshold from the Proposition. The derivation of $\bar{\chi}$ follows the same logic with $k_{\tau>0}$.

Proof of Proposition 2: For a given level of $\chi$ the threshold $\underline{s}<0$ implies that firms with $s<\underline{s}$ are not subject to taxation for any choice of $k$, i.e. $\pi^{b}(k, \varepsilon)+s<0 \quad \forall k$. The firm's optimality condition holds with equality and from $(10)$ it follows that $f^{\prime}(k)=\frac{1-\rho}{\rho \cdot\left(1-\left(1-\delta^{-}\right) V_{s} / p\right)}+\delta$. The optimal choice of capital is given by $k_{\tau=0}^{s}=\left(\frac{\phi \chi}{r_{s}}\right)^{\frac{1}{1-\phi}}$ with $r_{s}=\frac{1-\rho}{\rho\left(1+\left(1-\delta^{-}\right) V_{s}\right)}+\delta$. A positive derivative $V_{s}$ implies a higher cost of capital $r_{s}$. From Table 3 it follows that $V_{s}=\tau>0$ when $s<0$. Hence $k_{\tau=0}^{s}<k_{\tau=0}$. The derivation of $\bar{s}$ follows the same steps. For $s>0$ it follows that $V_{s}=-\tau<0$ and hence $k_{\tau>0}^{s}>k_{\tau>0}$.

\section{B - Model without profit taxation}

In the frictionless economy there are no taxes and hence no role for carry overs. Then we can write the firm problem as

$$
V(\varepsilon)=\max \left\{V^{c}(\varepsilon), V^{x}\right\}
$$

with $V^{x}=0$ and

$$
V^{c}(\varepsilon)=\max _{k, n}\left\{-p k(1-\rho)+\rho \mathbb{E}\left[p \varepsilon k^{\alpha} n^{\beta}-w n-p c_{f}-p \delta k+V\left(\varepsilon^{\prime}\right)\right\}\right]
$$

The optimal policy functions for labor and capital can be written as

$$
\begin{aligned}
& n(\varepsilon)=\left[\frac{\beta^{1-\alpha} \alpha^{\alpha}}{\bar{w}^{1-\alpha} r^{\alpha}}\right]^{\frac{1}{1-\gamma}} \varepsilon^{\frac{1}{1-\gamma}} \\
& k(\varepsilon)=\left[\frac{\beta^{\beta} \alpha^{1-\beta}}{\bar{w}^{\beta} r^{1-\beta}}\right]^{\frac{1}{1-\gamma}} \varepsilon^{\frac{1}{1-\gamma}},
\end{aligned}
$$

with $\bar{w} \equiv \frac{w}{p}=\beta \varepsilon k^{\alpha} n^{\beta-1}$ and $r \equiv \frac{1-\rho}{\rho}+\mathbb{E}[\delta]=\alpha \varepsilon k^{\alpha-1} n^{\beta}$. Combining these functions, a firm's 
revenue is given by

$$
s(\varepsilon)=p^{\frac{1-\alpha}{1-\gamma}} \varepsilon^{\frac{1}{1-\gamma}}\left(\frac{\alpha}{\mathbb{E}[r]}\right)^{\frac{\alpha}{1-\gamma}}\left(\frac{\beta}{w}\right)^{\frac{\beta}{1-\gamma}} .
$$

The value of a continuing firm is then given by

$$
V^{c}(\varepsilon)=\rho \mathbb{E}\left[s(\varepsilon) \cdot(1-\beta-\alpha)-\rho p c_{f}+\rho V\left(\varepsilon^{\prime}\right)\right] .
$$

Frictionless aggregate output can be written as

$$
Y^{*}=\left[M^{*} \Gamma \cdot \int \varepsilon^{\frac{1}{1-\alpha-\beta}} d F(\varepsilon)\right]^{1-\alpha-\beta} K^{\alpha} N^{\beta},
$$

where $M^{*} \Gamma$ is the total mass of firms in the economy.

To analyze the model with a VAT, note that if we define $\hat{\varepsilon} \equiv\left(1-\tau_{s}\right) \varepsilon$, this is the same problem as the frictionless model above, where $\tau_{s}$ is the VAT. After-tax sales are given by $\hat{s}(\varepsilon) \equiv$ $(1-\tau)^{\frac{1}{1-\gamma}} \cdot s(\varepsilon)$.

Firm value is then given by

$$
V(\varepsilon)=\rho \mathbb{E}\left[\hat{s}(\varepsilon) \cdot(1-\beta-\alpha)-\rho p c_{f}+\rho V\left(\varepsilon^{\prime}\right)\right]
$$

\section{C - Sensitivity Analysis and Additional Simulations}

\section{Selectively eliminating carry backs or carry forwards}

We consider two experiments in which we selectively shut off either carry forwards or carry backs, by setting $\delta^{-}=1$ or $\delta^{+}=1$. Results are shown in Table 8 . We find that the positive output effects reported in Table 6 mainly stem from the elimination of loss carry forwards. Eliminating carry backs has smaller, albeit positive effects. Firms that claim tax rebates in the benchmark economy are on average smaller and less productive. However, because losses can only be carried back two years, the effect of this distortion to marginal tax rates is limited.

\section{Exogenous exit}

Letting firm exit be stochastic allows us to shut down the selection margin from the benchmark results presented in the main text. To re-calibrate the model we remove the exit rate of $10 \%$ from the set of moments and instead add the estimated AR(1) process for the incidence of negative net income. Using the Compustat data, we find its persistence to be 0.59 year-to-year. The results of 
Table 8: Revenue-neutral Policy Experiments

\begin{tabular}{llcc}
\hline Moment & Benchmark & $\begin{array}{c}\text { No Carry } \\
\text { Forwards }\end{array}$ & $\begin{array}{c}\text { No Carry } \\
\text { Backs }\end{array}$ \\
\hline Output $Q^{*}$ (real) & 1.00 & 1.02 & 1.00 \\
Average TFP & 1.00 & 1.01 & 1.00 \\
Agg. Capital Demand & 1.00 & 1.01 & 1.00 \\
Agg. Labor Demand & 1.00 & 1.00 & 1.00 \\
Price Level $p$ & 1.00 & 0.98 & 1.00 \\
Firms paying taxes (share) & 0.37 & 0.51 & 0.36 \\
Entry / exit rate & 0.10 & 0.11 & 0.10 \\
Tax Revenue $T^{*} / Q_{\text {bench }}^{*}$ & 0.09 & 0.09 & 0.09 \\
Tax rate $\tau$ & 0.35 & 0.29 & 0.34 \\
Average MTR & 0.18 & 0.21 & 0.14 \\
VA-weighted $\sigma_{M P K}$ & 0.013 & 0.003 & 0.016 \\
\hline
\end{tabular}

Note.- The level of real output, TFP, capital demand, and the price level have been normalized to one in the benchmark. The tax revenue is normalized by the level of output in the benchmark economy. $\sigma_{M P K}$ refers to the value-added weighted standard deviation of marginal products of capital.

the calibration are shown in Table 9. The fit is slightly worse than that of the benchmark model because of the inclusion of the additional data moment. With exogenous exit, the negative value of $c_{e}$ implies that firms are making a loss on expectation. The results of the policy experiments are shown in Table 10 .

Table 9: Calibration Summary: Exogenous Exit case

\begin{tabular}{cclcc}
\hline Parameter & Value & Target & Data & Model \\
\hline$c_{e}$ & -67.88 & Fraction of firms running a loss & 0.49 & 0.53 \\
$c_{f}$ & 23.55 & Persistence of negative $\pi$ & 0.53 & 0.48 \\
$\sigma_{\varepsilon}$ & 0.08 & Fraction of firms paying taxes & 0.33 & 0.33 \\
$\delta_{0}$ & 0.0003 & Fraction of net income taxed & 0.85 & 0.85 \\
$\delta_{1}$ & -8.12 & Average depreciation rate & 0.08 & 0.08 \\
\hline
\end{tabular}

\section{Debt Financing}

In the benchmark model, firms were assumed to be exclusively using equity financing. In reality, a significant proportion of investment is debt-financed. Because of the tax advantage of debt, this lowers the tax burden on capital. To assess the sensitivity of our quantitative results to our financing 
Table 10: Revenue-neutral Policy Experiments with Exogenous Exit

\begin{tabular}{llcc}
\hline Moment & Benchmark & No carry overs & Value-added tax \\
\hline Output $Q^{*}($ real $)$ & 1.00 & 1.01 & 1.07 \\
Average TFP & 1.00 & 1.00 & 1.01 \\
Agg. Capital Demand & 1.00 & 1.05 & 1.29 \\
Agg. Labor Demand & 1.00 & 1.00 & 1.00 \\
Tax Revenue $T^{*} / Q_{\text {bench }}^{*}$ & 0.04 & 0.04 & 0.04 \\
Price Level $p$ & 1.00 & 0.99 & 0.97 \\
Firms paying taxes (share) & 0.33 & 0.48 & 1.00 \\
Entry / exit rate & 0.10 & 0.10 & 0.10 \\
Tax rate $\tau$ & 0.35 & 0.25 & 0.04 \\
Average MTR & 0.13 & 0.12 & 0.04 \\
VA-weighted $\sigma_{M P K}$ & 0.028 & 0.015 & 0 \\
\hline
\end{tabular}

Note.- The level of real output, TFP, capital demand, and the price level have been normalized to one in the benchmark. The tax revenue is normalized by the level of output in the benchmark economy. For the case of the value-added tax, the tax rate $\tau$ and the average MTR refer to the revenue-neutral value-added tax. $\sigma_{M P K}$ refers to the value-added weighted standard deviation of marginal products of capital.

assumption, we introduce an exogenous leverage ratio $\lambda$. A fraction $\lambda$ of capital is now financed with debt and the accruing interest payments are deducted from taxable income. Using the Flow of Funds data for non-financial corporate businesses between 1984-2015, we set the leverage ratio to $29.3 \%$. We then recalibrated the model to match the same set of moments as in the benchmark analysis. The results of this exercise are shown in Table 11. The resulting fit of the model with exogenous leverage is very similar to the benchmark calibration.

Table 11: Calibration Summary: Sensitivity Analysis - Leverage

\begin{tabular}{cclcc}
\hline Parameter & Value & Target & Data & Leverage Model \\
\hline$c_{e}$ & 100.00 & Entry \& exit rate & 0.10 & 0.10 \\
$c_{f}$ & 20.96 & Fraction of firms with $\pi^{b}<0$ & 0.49 & 0.51 \\
$\sigma_{\varepsilon}$ & 0.17 & Fraction of firms paying taxes & 0.33 & 0.35 \\
$\delta_{0}$ & 0.0004 & Fraction of net income taxed & 0.85 & 0.85 \\
$\delta_{1}$ & -7.74 & Average depreciation rate & 0.08 & 0.08 \\
\hline
\end{tabular}

Using these parameters, we repeated the main policy experiments (removal of loss-offset provisions, replacement of the corporate income tax with a sales tax). The results are shown in Table 12 . The reforms' estimated output gains are slightly subdued by debt-financing and the tax advantage of debt. Eliminating loss-offset provisions now increases output by $1.7 \%$, whereas replacing 
the corporate income tax with a sales increases output by $12.3 \%$.

Table 12: Revenue-neutral Policy Experiments - Leverage

\begin{tabular}{llcc}
\hline Moment & Benchmark & $\begin{array}{c}\text { No } \\
\text { Loss-Offset }\end{array}$ & $\begin{array}{c}\text { Value- } \\
\text { Added Tax }\end{array}$ \\
\hline Output $Q^{*}$ (real) & 1.00 & 1.02 & 1.12 \\
Average TFP & 1.00 & 1.01 & 1.01 \\
Agg. Capital Demand & 1.00 & 1.02 & 1.28 \\
Agg. Labor Demand & 1.00 & 1.00 & 1.00 \\
Price Level $p$ & 1.00 & 0.98 & 0.96 \\
Firms paying taxes (share) & 0.35 & 0.49 & 1.00 \\
Entry / exit rate & 0.10 & 0.12 & 0.12 \\
Tax Revenue $T^{*} / Q_{\text {bench }}^{*}$ & 0.08 & 0.08 & 0.08 \\
Tax rate $\tau$ & 0.35 & 0.26 & 0.07 \\
Average MTR & 0.17 & 0.15 & 0.07 \\
VA-weighted $\sigma_{M P K}$ & 0.011 & 0.002 & 0 \\
\hline
\end{tabular}

Note.- The level of real output, TFP, capital and labor demand, as well as the price level have been normalized to one in the new benchmark, where the leverage ratio $\lambda=0.293$. The tax revenue is normalized by the level of output in the benchmark economy. For the case of the value-added tax, the tax rate $\tau$ and the average marginal tax rate refer to the revenue-neutral value-added tax. $\sigma_{M P K}$ refers to the value-added weighted standard deviation of marginal products of capital.

\section{D - Data Appendix}

The main source used for the empirical results in Section 2 is the Compustat database, which provides balance sheet information on publicly listed companies in the US. The supplementary data on marginal tax rates is taken from Graham and Mills (2008) and is referred to as the GM data below. The sample selection criteria and the definition of the variables used in the analysis are as follows.

Sample Selection The first criterion for selecting the observations for analysis is the availability of the tax rates in the GM data. We drop firms that ever had a 50 percent or a larger share of its sales contributed by mergers and acquisitions (M\&A). In addition we drop any year during which the company had an M\&A activity. We delete observations from regulated firms (SIC 4900 and 4999). Our sample for regression analysis is comprised of all the remaining firms that have positive data on sales, valid data on employment, assets of $\$ 500,000$ or more and an estimated capital stock of at least $\$ 100,000$.

The key variables for estimating the firm level productivity are the firm level value added, 
employment, and physical capital. Firm level data is supplemented with the implicit price deflator for nonresidential fixed investment in the private sector to compute the capital stock.

Capital Stock The capital stock is constructed using inventory methods and the available information on gross and net property, plant, and equipment (PPEGT and PPENT). Specifically, we start with the first year in which PPEGT and PPENT are available for each firm. We then build the capital stock by adding the change in PPENT deflated by the investment price deflator to the calculated capital stock for that year.

Productivity We estimate firm level TFP following the Olley and Pakes (1996) method using capital expenditures as a control variable. We define output as sales plus the change in inventories. In the first step, we regress log output on second order polynomials in the logs of capital stock and investment expenditures including an interaction term as well as log employment. We control for a full set of indicator variables for year and industry at the 2-digit level of the NAICS classification. Sectors with fewer than 100 observations were excluded from the sample. To correct for survival bias, we estimate a probit specification for survival in the Compustat on the same polynomials as well as indicator variables for year and industry. In the third step, we estimate capital shares for each industry by regressing log output on the log of capital stock, controlling for industry-year effects and the predicted survival probability from the previous step. We then compute log TFP assuming a Cobb-Douglas production function and normalize it to have a mean of zero in each year and industry. 